Document downloaded from:

http://hdl.handle.net/10251/104006

This paper must be cited as:

Benajes, J.; Olmeda, P.; Martín, J.; Blanco-Cavero, D.; Warey, A. (2017). Evaluation of swirl effect on the Global Energy Balance of a HSDI Diesel engine. Energy. 122:168-181. doi:10.1016/j.energy.2017.01.082

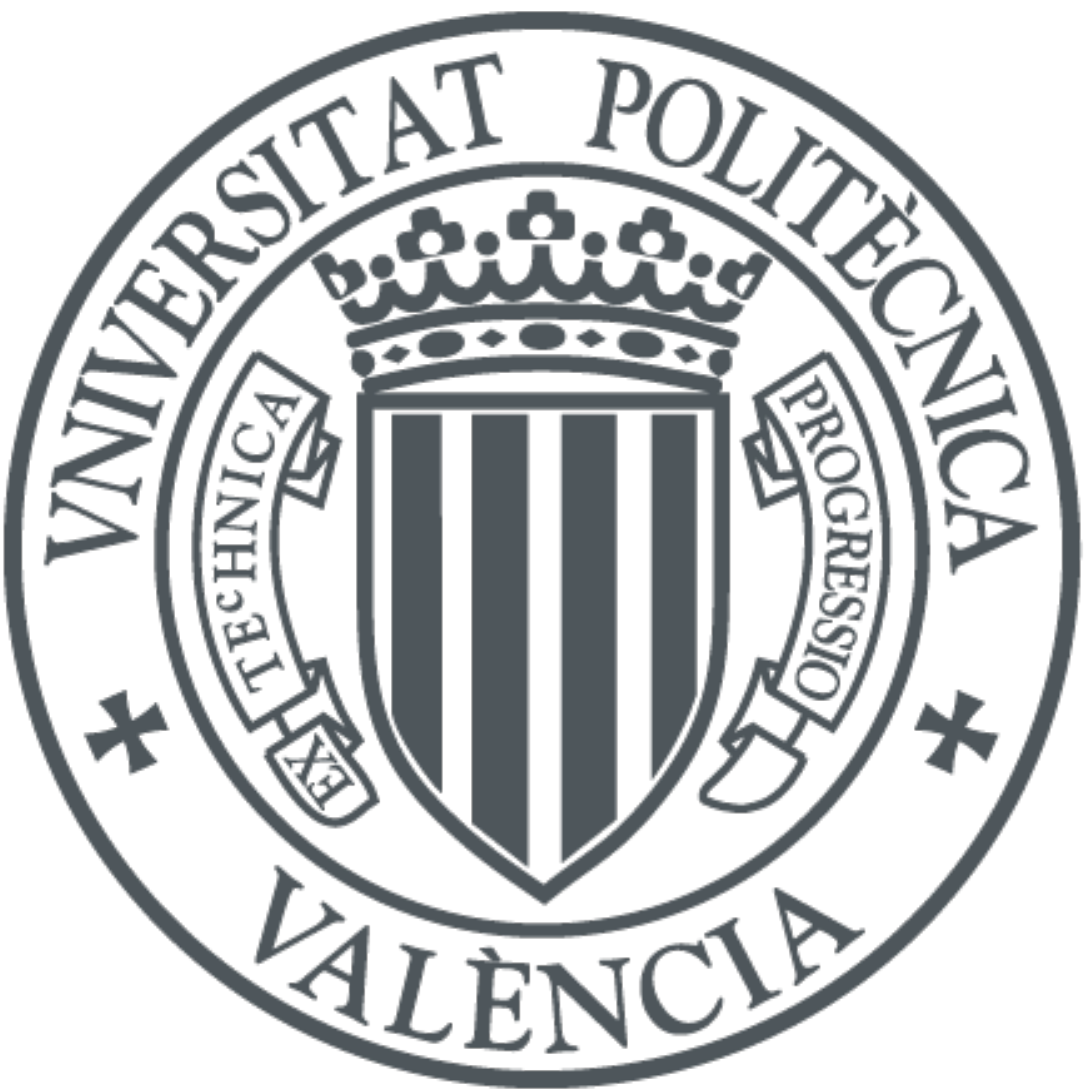

The final publication is available at

http://dx.doi.org/10.1016/j.energy.2017.01.082

Copyright Elsevier

Additional Information 
Document downloaded from:

http://hdl.handle.net/10251/104006

This paper must be cited as:

Benajes, J.; Olmeda, P.; Martín, J.; Blanco-Cavero, D.; Warey, A. (2017). Evaluation of swirl effect on the Global Energy Balance of a HSDI Diesel engine. Energy. 122:168-181. doi:10.1016/j.energy.2017.01.082

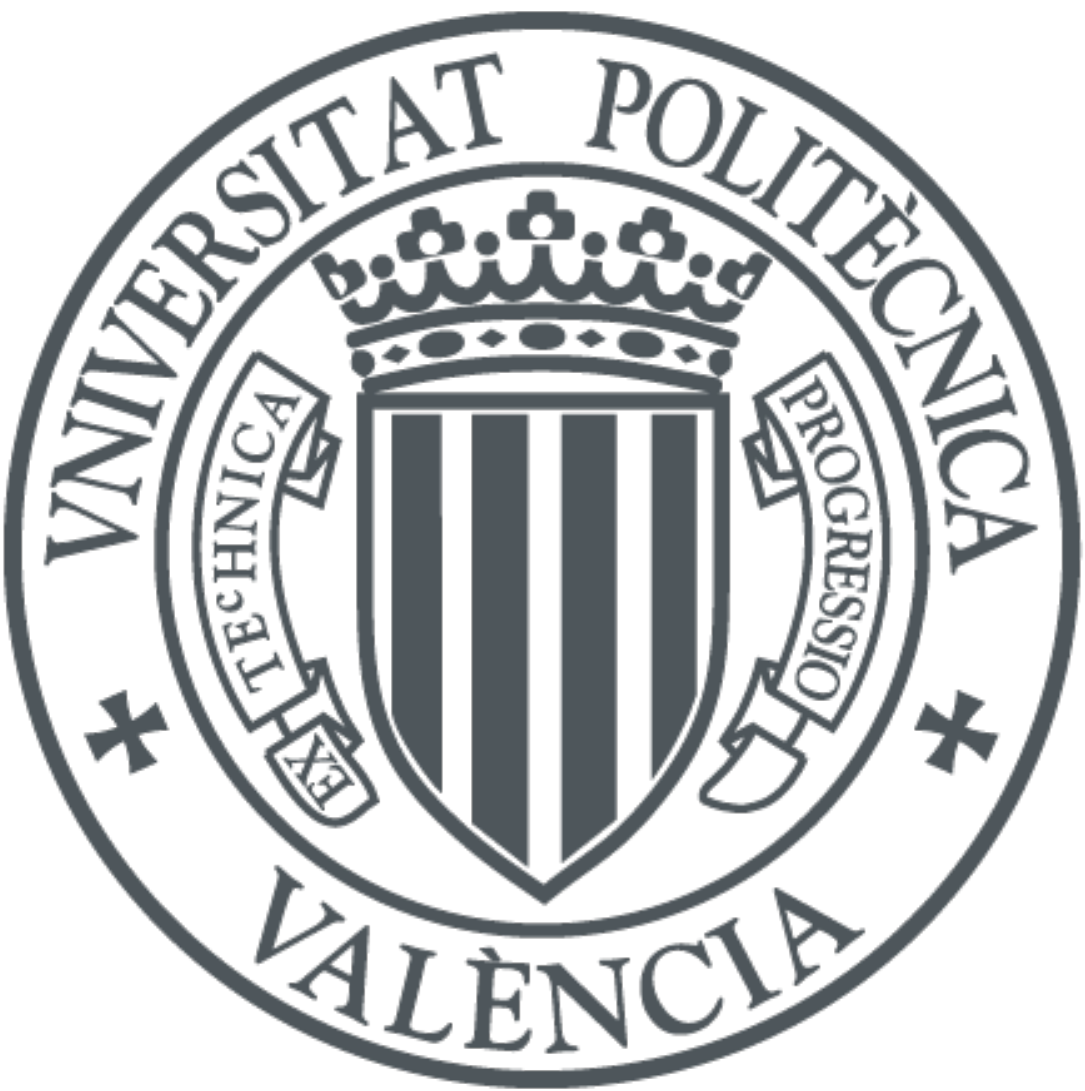

The final publication is available at

http://dx.doi.org/10.1016/j.energy.2017.01.082

Copyright Elsevier

Additional Information 


\title{
Evaluation of Swirl Effect on the Global Energy Balance of a HSDI Diesel Engine
}

\author{
Jesús Benajes $^{\mathrm{a}}$, Pablo Olmeda ${ }^{\mathrm{a}}$, Jaime Martín ${ }^{\mathrm{a}, *}$, Diego Blanco-Cavero ${ }^{\mathrm{a}}$, Alok Warey ${ }^{\mathrm{b}}$ \\ ${ }^{a}$ CMT-Motores Térmicos, Universitat Politècnica de València, Camino de Vera s/n, 46022, Valencia, Spain \\ ${ }^{b}$ GM Global Research and Development, Pontiac, USA
}

\begin{abstract}
In the last years, a growing interest about increasing engine efficiency has led to the development of new engine technologies. Since air motion in the chamber is a key issue in ICE to improve the air-fuel mixing process and achieve faster burning rates, modern Diesel engines are designed to generate gas vorticity (swirl) that lead to enhanced turbulence in the combustion chamber. However, the use of swirl has a direct effect on fuel consumption due to the changes in the in-cylinder processes, affecting indicated efficiency, and also on the air management. An analysis, based on the engine Global Energy Balance (GEB), is presented to thoroughly assess the behavior of a HSDI Diesel engine under variable swirl levels at different operating points. The tests have been performed keeping constant both the conditions at IVC and combustion phasing, thus minimizing the variability due to in-cylinder conditions and the combustion process. The analysis includes a combination of theoretical (OD models) and experimental tools (heat rejection and wall temperature measurement) used to ensure control of in-cylinder conditions and to provide detailed explanation of the different phenomena affecting engine efficiency when swirl rate is modified. Based on these tools, impact of swirl on the engine GEB is analyzed in detail paying special attention to engine efficiency and heat transfer in the chamber. Results show that increasing swirl has two main effects regarding the gross indicated efficiency $\left(\eta_{i}\right)$ : on one hand chamber heat rejection increases and therefore $\eta_{i}$ diminishes about $-0.5 \%$ at low load and $-0.4 \%$ at high load; on the other hand combustion development is affected and thus a $\eta_{i}$ improvement higher to $1.5 \%$ is achieved at low load and speed. The combination of these effects leads to a gross indicated efficiency increase higher to $1 \%$ at an optimum swirl ratio that diminishes when engine speed increases. In addition, pumping losses effect dominates brake efficiency behavior, which always diminishes (from $-0.9 \%$ to $-1.4 \%$ ) when swirl increases.
\end{abstract}

Keywords: Engine, Heat Transfer, Swirl, Global Energy Balance, Split of Losses

${ }^{*}$ Corresponding author. Tel: +34963877650 ; fax: +34963877659

Email address: jaimardi@mot.upv.es (Jaime Martín)

URL: www. cmt.upv.es (Jaime Martín) 


\section{Nomenclature}

\begin{tabular}{|c|c|}
\hline & ake efficiency .. \\
\hline$\eta_{i}$ & Gross indicated efficiency \\
\hline & Piston mean speed \\
\hline & Tangential vortex speed .... \\
\hline$C_{W 1}$ & Heat transfer coefficient $1 \ldots$ \\
\hline$C_{W 2}$ & Heat transfer coefficient 2 . \\
\hline$D$ & Cylinder diameter ........ \\
\hline & Heat transfer coefficient \\
\hline$\dot{H}_{b b}$ & Blow-by sensible enthalpy flow . \\
\hline$\dot{H}_{g}$ & Net sensible enthalpy flow of exhaust gases . \\
\hline$\dot{H}_{i c}$ & Incomplete combustion energy term \\
\hline$H_{V}$ & Net Heating Value \\
\hline & Air mass flow rate $\ldots . . .$. \\
\hline$\dot{m}_{e x h}$ & Exhaust gases mass flow rate. \\
\hline & Fuel mass flow rate $\ldots \ldots \ldots \ldots$ \\
\hline$N_{a}$ & Auxiliary power consumption \\
\hline & $\ldots[W],\left[\% m_{f} H\right.$ \\
\hline$N_{f r}$ & Friction losses \\
\hline$N_{i}$ & Gross indicated power .. \\
\hline$N_{m}$ & Mechanical losses . \\
\hline$N_{p}$ & Pumping power..... \\
\hline & In-cylinder pressure \\
\hline$\dot{Q}_{a}$ & Heat transfer in the intercooler ... \\
\hline$\dot{Q}_{\text {cool }}$ & Heat transfer to coolant .......... \\
\hline$\dot{Q}_{E G R}$ & Heat transfer in the EGR cooler \\
\hline$\dot{Q}_{\text {ext }, \text { block }}$ & Heat transfer from the engine block to the ambient $\ldots[W],\left[\% m_{f} H_{v}\right.$ \\
\hline$\dot{Q}_{f}$ & Heat transfer to the returned fuel \\
\hline$\dot{O}$ & Heat transfer to oil. \\
\hline$\dot{Q}_{\text {ports }}$ & Heat transfer to ports ... \\
\hline$H R$ & Rate of Heat Release . \\
\hline & Temperature . \\
\hline & $\ldots$ \\
\hline
\end{tabular}




\begin{tabular}{|c|c|}
\hline Abbreviations & \\
\hline ATDC & After Top Dead Center \\
\hline BDC & Bottom Dead Center \\
\hline BMEP & Brake Mean Effective Pressure \\
\hline CAD & Crank Angle Degrees \\
\hline CA50 & Crank Angle in which $50 \%$ of the fuel mass is burned \\
\hline CA90 & Crank Angle in which $90 \%$ of the fuel mass is burned \\
\hline CFD & Computational Fluid Dynamics \\
\hline $\mathrm{CR}$ & Compression Ratio \\
\hline DI & Direct Injection \\
\hline EGR & Exhaust Gas Recirculation \\
\hline GEB & Global Energy Balance \\
\hline $\mathrm{HCCI}$ & Homogeneous Charge Compression Ignition \\
\hline HSDI & High Speed Direct Injection \\
\hline HT & Heat Transfer \\
\hline ICE & Internal Combustion Engine \\
\hline NEDC & New European Driving Cycle \\
\hline IVC & Intake Valve Closing \\
\hline PCCI & Premixed Charge Compression Ignition \\
\hline SOE & Start of Energizing Time \\
\hline SR & Swirl Ratio \\
\hline TDC & Top Dead Center \\
\hline VGT & Variable Geometry Turbine \\
\hline
\end{tabular}




\section{Introduction}

Global awareness towards greenhouse gases emissions has led to a more stringent ICE emissions legislation, thus focusing the automotive researchers and manufacturers attention on the development of cleaner and more efficient powertrains. In the last years, the efforts have been mainly focused on the reduction of $N O_{x}$ and soot emissions by means of different injection strategies [1], high pressure fuel injection systems [2], multiple injections [3], high boost pressure [4], exhaust gases recirculation (EGR) [5, 6], variable valve timing [7, 8], high swirl [9, 10] and tumble ratios $[11,12]$ and new clean fuels $[13,14]$. However, the impossibility to overcome the regulation only managing internal processes, has led to the generalization of after treatment systems [15], giving room to the other main engine issue: engine fuel consumption. Hence, there is an increasing interest towards the optimization of fuel consumption, and the reduction of $\mathrm{CO}_{2}$ emissions [16] by means of different technologies. To comply with the upcoming requirements, new combustion concepts such as HCCI [17] and PCCI [18], and new automotive engine concepts such as downsizing $[19,20]$, and two-stroke engines [21] are being studied. Air motion in the chamber is a common factor in these works, since it is a key issue to improve the air-fuel mixing process and achieve faster burning rates [15], therefore modern ICE are designed to generate vorticity in the chamber that leads to enhanced turbulence during the combustion development, thus affecting emissions and consumption.

The main air rotation macro structures that can be found in ICE are swirl and tumble, being differentiated by their rotary axis (swirl rotates around the cylinder axis while tumble around the diametrical axis). Both are generated during the intake process thanks to the ports geometry design and evolve during compression thanks to the combustion chamber configuration. In the case of swirl, there are two different kinds of intake ports, one of them is the tangential port, used to generate swirl motion, and the other one, helical port, generates low swirl motion and it has a higher flow capacity. During the compression stroke, the swirl movement is prompted by the chamber geometry consisting of a shallow bowl engraved into the piston crown [15] that allows accelerating the air rotation thanks to the partial momentum conservation.

A common technique used to get variable swirl consists in placing a throttle plate upstream of the helical port [22]. When high flow is required, this plate operates fully open achieving the lowest swirl ratio, while it gets completely closed when a high swirl level is required. High swirl conditions normally are used at low load and engine speed, when less amount of fresh air is necessary, while low swirl is set at high speed and load to reach a suitable air feeding through the helical port. In return, this technique has a big impact on the air management process since it produces a higher drop pressure in the helical port due to the control valve. This makes necessary a higher boost pressure to get the same trapped mass in the cylinder, therefore the turbine section must be reduced to reach the required intake pressure. These changes and derived consequences will be deeply evaluated in this study. 
Apart from the benefits on combustion enhancement, there are some disadvantages derived from the use of swirl. The main problem is the enhancement of heat transfer (HT) in the chamber due to the higher gas velocity that increases the heat transfer coefficient. The swirl characteristics have been widely studied, and most HT correlations include a term accounting for its contribution to the characteristic gas velocity used to calculate the HT coefficient $[23,24]$. Therefore, swirl leads to a contradictory scenario where it benefits efficiency through the improved combustion development and worsens it due to the increased HT. Thus, an adequate swirl level can be used to optimize the $\eta_{i}$, soot and $N O_{x}$ trade-off [25].

Several studies have analyzed the effects of swirl on combustion performance $[9,10,26,27]$ and on emissions $[28,29]$. All these works are based on either experimental single-cylinder engines or CFD studies focused on singlecylinder engines, so none of them takes into account the phenomena beyond the combustion chamber and, consequently, they do not consider all the processes affecting air management in a multicylinder engine. Furthermore, none of the single-cylinder engine studies has been focused on the swirl effects on the engine behavior from a global point of view, analyzing in detail the effects on all the relevant energy terms. To contribute to this issue, a comprehensive analysis of all the involved phenomena and the relationships between them is performed in this work.

The Global Energy Balance (GEB) [30] is a useful tool for identifying the paths followed by the chemical energy of fuel. The identification of this energy split will allow to determine the effect of swirl variation on different processes inherent to engine operation. This approach includes internal and external analysis of the engine and requires the use of both experimental measurements and internal modeling [31]. In this way, the measurable changes in the experimental variables can be explained through the analysis of internal processes that are modeled, especially heat transfer.

For the analysis, a multicylinder production Diesel engine with variable swirl, specially instrumented to perform the thermal measurements, was used in order to keep realistic thermal conditions. During the study, a detailed analysis at different swirl levels was carried out to thoroughly assess its impact on engine efficiency, heat rejection in the chamber and the GEB (external and internal). Finally, to quantify separately the effect of heat transfer and RoHR changes, a simple method based on the engine simulation with a 0D thermodynamic model was used.

\section{Experimental and theoretical tools}

\subsection{Engine characteristics}

The study was carried out in a HSDI Diesel engine, whose main characteristics are presented in Table 1. In spite of the more difficult control and possible cylinder dispersion in comparison with a single cylinder engine, a 4 cylinder engine was selected to replicate the thermal response of the production engine under different swirl levels. 
Modifications were done to some systems of the original engine to attain better control of the engine fluids, thus, the EGR and oil coolant circuits were separated from the engine coolant circuit. Therefore, heat rejection to oil, coolant, intercooler and EGR heat exchangers could be analyzed independently. Besides, the original air-air intercooler was replaced by an air-water heat exchanger. To provide information for the lumped conductance model commissioning and validation, 88 thermocouples were installed at different locations of the engine block and cylinder-head.

As commented, swirl ratio, defined as the ratio between air angular speed at the IVC and the crankshaft angular speed, can be varied by means of a valve located upstream of the helical port of each cylinder. When this valve is completely open, the air comes into the cylinder through both the tangential and helical ports leading to the lowest swirl ratio ( $\mathrm{SR}=1.38$ ). The more closed the valve gets, the lower the air mass flow through the helical port is, leading to a higher mass flow through the swirl generator port (tangential) and the consequent higher swirl ratio. The highest swirl level $(\mathrm{SR}=2.95)$ is reached when the valve is completely closed.

The engine control was performed by using a commercial controller system - DRIVVEN. This tool works as a conventional control unit and, additionally, it is able to acquire, analyze and record different instantaneous signals from the engine (e.g., in-cylinder pressure, intake and exhaust pressures, rail pressure and the current clamp signal corresponding to the injection command) as well as real-time control of different combustion variables such as combustion phasing that was kept constant during all the experimental swirl sweeps. DRIVVEN was used to control the engine settings by modifying the required parameters such as the EGR valve position, VGT position, injection quantity and timing, and swirl and throttle valves.

\subsection{Test cell characteristics}

The engine was installed in a fully instrumented test cell, which scheme is shown in Figure 1. The characteristics of the most relevant instrumentation are presented in Table 2. The installation was instrumented to acquire the standard measurements necessary to perform the complete combustion diagnosis and model the internal energy terms with an in-house developed tool called CALMEC [30, 32]; and the data required for the experimental external thermal balances [31]. In-cylinder pressure was measured with 4 Kistler 6125C piezo-electric transducers flush mounted in the glow plug hole of each cylinder. The signal provided by each sensor was conditioned with a Kistler 5011B amplifier and then collected by DRIVVEN.

To perform the GEB, detailed heat fluxes to coolant, oil, intercooler and EGR cooler were obtained by means of specific instrumentation to measure fluid flows and temperatures. Furthermore, intake and exhaust conditions were measured in order to perform a detailed analysis of the in-cylinder conditions during both close and open cycle: air and fuel mass flows, gas temperatures and pressures at different intake and exhaust positions were recorded at low 
frequency $(10 \mathrm{~Hz})$ and then averaged.

\subsection{OD models}

During the present study two different 0D single-zone thermodynamic models (CALMEC and siCiclo) were used. Both of them share the same main hypothesis:

- Chamber pressure and temperature are assumed to be spatially uniform.

- Three species (air, fuel vapor and stoichiometric combustion products) are considered [33].

- Ideal gas law is used to calculate gas mean temperature.

- A filling and emptying model is used to calculate the trapped mass [34].

- Specific heat of the gas depends on both temperature and composition [35].

- Instantaneous blow-by leakage is calculated with a model based on the isentropic nozzle flow [34].

- Chamber volume deformation is calculated by means of a simple deformation model [36].

- Heat transfer to the chamber walls is calculated with a modified Woschni-like model [24].

An in-house methodology [32] was implemented to determine some experimental uncertainties related to incylinder pressure (pressure pegging and TDC position) along with some engine characteristics (dynamic and static compression ratios and HT convective model adjustment). Besides, a lumped conductance model was used to calculate wall temperatures in the chamber and ports along with the heat rejection repartition to coolant and oil. It consists of 102 nodes in the cylinder head, 66 in the liner, 10 in the piston and some boundary nodes that take into account the oil, coolant, fresh air, in-cylinder gas, and intake and exhaust gases. More details of this model can be seen at [37].

On the one hand, CALMEC is the combustion analysis tool that allows calculating the RoHR from the instantaneous evolution of in-cylinder gas properties by solving the $1^{\text {st }}$ law of thermodynamics and modeling the internal energy terms based on the instantaneous pressure evolution. The model considers all the relevant engine subsystems through the combination of both physical and semi-empirical submodels to calculate the heat transfer flow to combustion chamber walls and ports, split of mechanical losses and intake and exhaust processes [30].

On the other hand, siCiclo [33] is a predictive tool that, using the RoHR as main input, is able to calculate the pressure evolution with the purpose of predicting engine performance and fuel consumption or obtaining boundary conditions for specific combustion models with higher computational requirements [38, 39]. 


\section{Methodology}

The objective of this work is the assessment of swirl effect on the engine efficiency by means of the theoretical and experimental analysis of the GEB. The study was structured in three main parts, as explained in the next paragraphs:

- As engine losses are a key focus in this study, an initial calibration of the HT and mechanical losses model was performed. This was done using data from both motoring and combustion tests (not detailed here).

- Then, the experimental measurement of swirl sweep studies was performed in the installation described in the experimental tools section. The test campaign was performed at six different operating points in which four swirl rates were evaluated.

- Finally, an analysis of the swirl effect on the efficiency and the energy split is carried out using the GEB methodology, whose results are presented and discussed.

\subsection{Theoretical models adjustment}

An initial adjustment was carried out to ensure the accurate estimation of the heat transfer to different engine parts, where special attention was paid to the heat rejection in the combustion chamber. Thus, tests in motored conditions were used to adjust some uncertainties (real compression ratio, TDC position and the constant of the deformation model) along with the constants of the Woschni-like equation velocity term, $C_{W 1}$ and $C_{W 2}$ (see appendix). The adjustment method is based on the application of the first law of thermodynamics to obtain the RoHR residuals (it should be zero because no fuel is injected). A multi-variable linear regression is used to find the values of the parameters by means of the least square method. More details of the process can be found in [32].

Once $C_{W 1}$ and $C_{W 2}$ were adjusted in motoring conditions, both of them along with $C_{2}$ (see appendix) were refined using tests in combustion throughout the whole engine map. The criterion followed during this step was to set the apparent combustion efficiency close to $100 \%$.

Geometry of the lumped conductance model [40] nodes was adjusted to fit the real engine geometry and to facilitate the comparison between experimental and modeled nodes temperatures (in the locations where thermocouples were installed at the cylinder-head and liner). Once the lumped model was built and included in the 0-D models, the experimental temperatures obtained with the thermocouples were used to validate the results provided by the lumped conductance model, obtaining a mean error about $5^{\circ} \mathrm{C}$ and a maximum error lower than $10^{\circ} \mathrm{C}$ in most cases.

\subsection{Test methodology of swirl sweeps}

To assess the swirl effect, a study was carried out at six different operating points (k-points). These k-points were chosen for being the most representative of an emission homologation cycle (NEDC). In the present work these k- 
points will be named by using a composition of 2 numbers, the first one means the engine speed in revolutions per minute while the second one refers to the BMEP in bar (engine speed_BMEP). Their most significant variables can be seen in Table 3. For the sake of brevity, and taking into account that k-points can be grouped according to their behavior, only three of them (1500_8, 1500_14 and 3000_14) will be analyzed in detail. Since 1500_8, 2000_2 and 2000_5 points have a similar behavior, it was decided to show 1500_8 (intermediate load). It was found another group with similar trends which consists of 2000_15 and 3000_14, from which the last k-point was chosen. The last studied k-point was 1500_14 that shows an intermediate behavior between the 2 previous groups. In this way, the study shows a load sweep at constant speed (1500 rpm) and an engine speed sweep at constant load (14 bar).

Swirl ratio was variated from 1.38 to 2.95 in 4 levels $(1.38 / 2 / 2.5$ / 2.95). These ratios were provided by the engine manufacturer. Hence, the complete test matrix is composed of 6 (k-points) x 4 (swirl levels) x 3 repetition of each point, although only 3 of the k-points will be shown here.

To isolate the effects of swirl variation, all engine parameters except this one were kept constant. Therefore, swirl sweeps were performed with the same intake temperature $\left(45^{\circ} \mathrm{C}\right)$ and trapped mass at the IVC, as well as the same combustion phasing (CA50 $=13^{\circ}$ ATDC) and injected fuel mass, which was fixed for each k-point. Regarding the intake pressure, it was adjusted at each swirl level to get the same inlet mass flow (see Experimental and theoretical tools section). Furthermore, coolant $\left(87^{\circ} \mathrm{C}\right)$ and oil $\left(95^{\circ} \mathrm{C}\right)$ temperatures were kept constant in all the tests, thus avoiding interferences in the heat fluxes and friction losses when the swirl sweeps were performed.

With respect to the injection strategy, it consists of two pilot injections to reduce the combustion noise and a main injection event. Pilot quantities $(1.5 \mathrm{mg} / \mathrm{cc})$ and dwell times $(0.8 \mathrm{~ms})$ were kept constant for all the points. On the other hand, the main injection quantity was varied to meet the required BMEP at each k-point and the timing of this injection was set to obtain a CA50 of $13^{\circ}$ in each test. Hence, the complete injection train was moved with swirl changes as can be seen in Table 3 .

To ensure a stable thermal behavior of the engine, stabilization periods between 20 and 40 minutes were required. It was assumed that thermal stabilization was reached when the temperature variation rate of all the liquids (coolant, cooling water and oil) was lower than $1^{\circ} \mathrm{C} / \mathrm{min}$. The thermal stabilization was evaluated in the liquids instead of the material for two reasons. On one hand, liquids reached their thermal stabilization later than engine material due to the higher thermal inertia and the high thermal diffusivity of the metal. Thus, when the liquid stabilization was reached, metal temperature was also stable. On the other hand, liquids temperature are measured with thermoresistances, which are more accurate than the thermocouples used to measure cylinder-head and cylinder liner temperatures. Gas temperatures (intake air and exhaust gases) were also controlled, but their stabilization was faster than in the case of liquids, thanks to the lower thermal inertia and the higher convective HT between those fluids and the measurement 
devices (thermocouples and thermoresistances).

\subsection{Analysis of swirl effect on GEB}

The GEB (see scheme in Figure 2) was used to evaluate the effect of changing the swirl ratio. All the energy transformations and thermal processes taking place in a DI Diesel engine are considered. Following, a brief description of the analyzed terms is provided in the following subsections.

\subsubsection{External GEB}

From the external point of view (outside the dash line in Figure 2), the engine was considered as a black box with some energy flows entering and some others leaving it. Since these flows are external they can be directly measured and used for the validation and completion of the internal analysis, which is mainly based on theoretical models.

The terms included in the external GEB are thoroughly explained in [30]. In brief, the main input is the fuel chemical power $\dot{m}_{f} H_{v}$. The main outlet energy flows are the brake power $N_{b}$, the heat flow to the coolant $\dot{Q}_{\text {cool }}$, the net sensible energy of the exhaust gases $\dot{H}_{g} \approx\left(\dot{m}_{\text {exh }} h_{\text {exh }}^{\text {sens }}-\dot{m}_{a} h_{a}^{\text {sens }}-\dot{m}_{f} h_{f}^{\text {sens }}\right)$, the heat flow rejected to the oil exchanger $\dot{Q}_{o i l}$, the heat flow in the intercooler $\dot{Q}_{a}$ and the heat flow rejected to the EGR cooler $\dot{Q}_{E G R}$. Other outlet terms with lower importance are the convective and radiative HT to the ambient from the engine external surface $\dot{Q}_{\text {ext,block }}$, the enthalpy flow due to blow-by losses (externally collected) $\dot{H}_{b b} \approx\left(\dot{m}_{b b} h_{b b}^{\text {sens }}\right)$, the energy losses due to incomplete combustion $\dot{H}_{i c}$ and the heating of the fuel returning to the tank $\dot{Q}_{f}$. Since the importance of these last terms are low, they were included, along with the experimental uncertainties, in a miscellanea term called $\dot{Q}_{m i s c}$.

\subsubsection{Internal GEB}

Unlike the terms involved in the external GEB, those related to the internal GEB (inside the dash line in Figure 2) cannot be easily measured, except the indicated power that can be obtained from in-cylinder pressure. Thus, to obtain an accurate estimation of the rest of terms, several submodels [30] (dealing with engine heat transfer and mechanical losses) were necessary in combination with the available experimental in-cylinder pressure. As detailed, these submodels are included in the in-house developed OD combustion diagnosis tool (CALMEC) used during this study.

The internal GEB includes the following main terms: the indicated power $N_{i}$, which is split into brake power $N_{b}$ and mechanical losses $N_{m}$ (due to the pumping power $N_{p}$, friction losses $N_{f r}$ and the auxiliary losses $N_{a}$-fuel, oil and cooling pumps-). Regarding the heat rejection in the chamber, main issue in the work, the heat flow to the chamber is calculated through the lumped model, thus obtaining the heat transfer to coolant $\dot{Q}_{\text {cham,cool }}$, oil $\dot{Q}_{c h a m, o i l}$ and ports 
$\dot{Q}_{\text {ports }}$.

The combination of internal and external balances allowed the complete characterization of the swirl effect.

\section{Results and discussion}

In this section the experimental and modeled results, along with the discussion regarding the swirl effect is presented. Graphs show mostly experimental results, provided that they are available. Modeled results will be discussed when experimental results are not available. Figure 3 shows the GEB of the three k-points with the lowest swirl ratio, which will be the reference points for the analysis. In the left-hand graph, the power of the different energy terms is represented, while in the right part their relative value in percentage of the total fuel energy is plotted. As shown at the left plot, the three k-points are clearly different, being the fuel power $56 \mathrm{~kW}, 97 \mathrm{~kW}$ and $184 \mathrm{~kW}$ respectively.

In relative terms, it can be highlighted a higher brake efficiency in the 3000_14 case (38.6\% in this last case vs 37.3\% and 35.9\% at 1500_8 and 1500_14 respectively). Regarding the heat transfer to coolant and oil, a decrease with load and engine speed can be observed. While this term represents the $29 \%$ of the fuel energy in the 1500_8 case (18.9\% to coolant and $10.1 \%$ to oil), it is about $26.2 \%$ in the $1500-14$ test (16.8\% to coolant and $9.4 \%$ to oil).

These trends are in agreement with the expected behavior; on the one hand, increasing the load (from BMEP $=8$ to 14) leads to higher gas temperature, thus the difference between mean gas and wall temperatures (proportional to the heat flow) increases about $20 \%$. Besides, the heat transfer coefficient augments by $30 \%$ mainly due to the higher pressure. As a consequence, the heat transfer to chamber walls is 1.5 times higher. However, the fuel power is 1.7 times higher at 1500_14 with respect to 1500_8, thus the higher the load the lower the relative weight of the heat transfer. On the other hand, an increase on engine speed leads to higher heat transfer coefficient in the chamber, which is proportional to $c_{m}$ powered to $a<1$ (according to the convection correlations -see appendix-). However, the available time for heat transfer is inversely proportional to $c_{m}$ and therefore it becomes the key factor.

With respect to heat transfer in the intercooler, the load seems to dominate the trends, thus it is about $3 \%$ in the two 14 bar BMEP k-points while its weight was lower at the lowest load (1.4\%). This was consequence of the higher boost pressure reached in those high load k-points (1.73 bar and 1.93 bar in 1500_14 and 3000_14 respectively, whilst it was 1.33 bar at low load). If exhaust gases sensible enthalpy is analyzed, it seems to be dependent on speed, thus 3000 14 had the highest value (33.6\%), unlike the other two where this term is about $26.5 \%$ of the total fuel energy. This big difference can be explained by the hotter exhaust temperature produced by the longer combustion (in CAD) because of the higher load and engine speed and the lower relative chamber heat rejection. 
Finally, the miscellanea term $\dot{Q}_{\text {misc }}$ shows a global trend to diminish when the engine speed increases. This is mainly due to the reduction of the heat rejection to the ambient and the lower experimental uncertainties when measuring and computing (using fluid flow rates and temperatures) the thermal flows.

Once the external GEB of the reference k-points have been analyzed, the variation of energy terms due to swirl rate changes is evaluated. Firstly, the brake efficiency term and the sub-terms affecting this parameter are thoroughly assessed. Then, the HT to the different parts and fluids is evaluated. After that, the exhaust gases sensible enthalpy variation with swirl increment is presented. Finally, changes in other minor terms of the GEB when SR increases are analyzed.

\subsection{Brake efficiency}

Figure 4 shows the variation of brake efficiency, along with the parameters affecting it, in a swirl rate sweep in the 3 analyzed k-points. These variations are referred to the reference points shown in Figure $3(\mathrm{SR}=1.38)$ and the maximum variation of the repetitions is plotted at each point. Additionally, error bars, calculated as the maximum difference between the 3 repetitions and their average value, are plotted above and below the average value in the figure. In the three cases, increasing swirl rate led to a worse brake efficiency at the highest swirl level $(-1.2 \%,-1.4 \%$ and $-2.3 \%$ respectively). However, the trend with the SR is not monotonous, thus in the 1500_14 case there is a maximum $\eta_{b}$ at the intermediate level $(\mathrm{SR}=2)$, while in the other two k-points, intermediate swirl rates do not lead to a clear efficiency reduction. As Eq. (1) shows, brake power $\left(N_{b}\right)$ is the difference between gross indicated power $\left(N_{i}\right)$ and mechanical losses, i.e. pumping $\left(N_{p}\right)$, auxiliary $\left(N_{a}\right)$ and friction losses $\left(N_{f r}\right)$ and thus, its behavior can be analyzed taking into account these terms:

$$
N_{b}=N_{i}+N_{p}-N_{a}-N_{f r}
$$

where $N_{p}$ is negative (it is obtained by integrating $p d V$ from exhaust to intake BDC) while the rest of terms in (1) are positive.

Regarding the gross indicated efficiency $\left(\eta_{i}\right)$, increasing swirl rate enhances air-fuel mixing during the first stages of injection-combustion due to the higher air velocity which implies higher turbulent behavior. This mixture process improvement leads to an enhancement of the pilot and premixed combustion that can be seen in the sharper slope of the main RoHR up to its peak at the three k-points shown in Figures 5, 6 and 7 and also in the shorter delay time shown in Figure 8. As a consequence of this combustion enhancement, the pressure rate gets higher as can be seen in the bottom part of Figures 5, 6 and 7. This faster combustion has a positive effect on gross indicated efficiency, at least during the first combustion stage. 
With respect to the next stages of RoHR, their behavior is different depending on the load and engine speed. An enhancement of its peak with swirl can be seen at the lowest load k-point (1500_8) in Figure 5 where the higher air velocity helped to get a sharper slope and also a higher RoHR peak. However, this trend is not followed at the highest swirl ratio ( $\mathrm{SR}=2.95$ ), where the RoHR peak goes down. It has been checked that this behavior does not take place in all the repetitions and cycles but it is quite usual at this low load point. This phenomena can be related to the same explanation given to the swirl sweep at high load k-points (see below). At this k-point (1500_8), the RoHR just after the main peak was also releasing more heat when swirl increased leading to a higher fuel burn rate (up to $22^{\circ}$ ATDC), as seen in [41]. As a result of the described combustion behavior, the combustion duration tends to shorten, as can be observed in Figure 8 and, since CA50 is set at the same CAD, CA90 is reached earlier. This leads to a lower temperature at the end of the expansion (see Figure 9) and, consequently, to a lower exhaust temperature.

With regard to the other 2 k-points (high load), as can be seen in Figures 6 and 7, a lower RoHR peak was achieved when swirl increased, especially at $\mathrm{SR}=2.95$. This combustion velocity limitation contributes to worsen the RoHR evolution just after the peak, thus extending the CA90 and the combustion duration (Figure 8). As a consequence of the longer combustion duration, the exhaust gas temperature increased at these k-points when swirl was increased, as can be seen in the late part of the instantaneous gas temperature in Figure 9 and in the Exhaust gases sensible enthalpy section.

Although the accurate explanation of the combustion worsening at high load (also seen at low load and high SR) would require CFD calculations (out of this project scope) to clarify the involved phenomena, some hints will be given to focus the problem. On one hand, the high rotation motion promoted by high swirl ratios forces adjacent sprays to interact between them, thus worsening the air-fuel mixture process [42]. On the other hand, de la Morena et al. [43] found that high swirl ratios displace the combustion towards the squish region at high load, acting as a barrier and limiting the spray tip velocity and penetration. Thus, the spray is deflected towards the fire deck, preventing it from efficiently entraining fresh air in the piston bowl. Both phenomena are probably causing the observed RoHR trends, with an almost monotonous behavior at high load while it only affects at very high SR at low load.

Due to the air velocity increment achieved when swirl is increased, the heat transfer coefficient also increases leading to higher HT in the chamber, as shown in Figure 9. This effect can be clearly seen up to the heat rejection peak (about $15^{\circ} \mathrm{ATDC}$ ), where the effect of higher pressure and temperature due to the faster combustion at the initial stage is more evident. Heat transfer enhancement has a negative impact on gross indicated efficiency in all the three studied k-points.

As explained, RoHR changes can affect in contrary ways (combustion enhancement or worsening) at different combustion stages and operating conditions while HT always affects negatively gross indicated efficiency. The com- 
bination of both effects can be negative in some cases but also positive in some others leading to different behavior of $\eta_{i}$ (Figure 4). It can be seen that, in some cases, intermediate SR do not show a bad performance while some points show higher gross indicated efficiency even at maximum SR. To clarify this issue, a detailed analysis to assess the impact of these parameters (RoHR shape and heat transfer) on indicated efficiency was carried out at the extreme swirl levels. The predicting tool, siCiclo was used for this purpose. This study was performed according to a methodology based on the the split of losses [44] where, starting from the real measured indicated cycle, imperfections are eliminated step by step up to the ideal cycle. The study consists of 3 steps, which effects are graphically represented in Figure 10 and the results summarized in Table 4:

1. Original cycle: simulation of k-points in SiCiclo using experimental conditions ( $p, T$ and composition at intake valve closing and experimental RoHR). A discrepancy respect to experimental $\eta_{i}$ lower than $0.5 \%$ was achieved in all the cases. These reference values are shown in column 3 of Table 4, while the difference with respect to the simulation with lower SR is shown in the last column of the table and plotted in Figure 10.

2. Maintaining the RoHR (at each k-point and SR), the adiabatic cycle was calculated to assess the HT influence on $\eta_{i}$ at each swirl level, thus obtaining the maximum efficiency achievable in adiabatic conditions (column 4 in Table 4). The difference between the original and adiabatic cycles is the impact of HT on gross indicated efficiency (column 5 in Table 4) and the $\Delta \mathrm{HT}$ effect at each swirl level (column 6 in Table 4 and Figure 10) is computed as the difference of this HT impact between a certain SR and the lowest one.

3. Since experimental variables and IVC conditions are similar at all swirl levels, the adiabatic cycles (column 4 in Table 4) should reach the same $\eta_{i}$ for all swirl rates if the RoHR was the same. However, since combustion process is affected by SR (as shown in the previous subsection) it can be assumed that changes on $\eta_{i}$ in adiabatic conditions are produced by the different RoHR. This effect ( $\triangle$ RoHR effect) is plotted in Figure 10 and summarized in column 7 of Table 4.

It is important to take into account that this analysis has some limitations. On the one hand, the order in which these losses are computed may have an impact on their value (slightly different results would be obtained if RoHR was first assumed to be the same and then the effect of adiabatic cycle was computed). On the other hand, since heat transfer and RoHR effects are the only ones considered, the effect of other imperfections (such as the effect of variable heat capacity at constant volume) are implicitly included in the RoHR effect. Despite of these limitations, this method is a good way to quantify the benefits/drawbacks of each effect.

In the 1500_8 k-point, the $\eta_{i}$ increased almost linearly up to $1.2 \%$ at $\mathrm{SR}=2.5$ because of the combination of the combustion enhancement due to the sharper RoHR slope before the peak (1.7\% positive effect) and the $\Delta \mathrm{HT}$ effect (-0.5\%). However, at $\mathrm{SR}=2.95$ the $\Delta \mathrm{RoHR}$ effect drops deeply (as commented, the RoHR peak tends to diminish), worsening the $\eta_{i}$ in $-0.4 \%$. When the 1500_14 k-point is analyzed, a similar behavior with a $\eta_{i}$ maximum at $\mathrm{SR}=2.5$ is 
found, where a global positive effect of $0.8 \%$ on $\eta_{i}$ was reached. This improvement is explained by the fact that, on the one hand, the $\Delta \mathrm{HT}$ effect only produced a $-0.3 \%$ reduction in the gross indicated efficiency (lower than at low load), while the sharper RoHR slope at the main combustion starting had a bigger impact on $\eta_{i}$ than the lower RoHR peak, leading to an improvement of $\Delta \mathrm{RoHR}=1.1 \%$ (lower than at 1500_8 due to the RoHR peak worsening). Similarly to the previous k-point, a decrease of $\eta_{i}$ at the highest SR is observed, although in this case it is smoother, thus still having a positive effect with respect to $\mathrm{SR}=1.38(\Delta \mathrm{RoHR}=0.3 \%)$.

In the case of 3000_14, the $\Delta$ RoHR effect tends to increase slightly $\eta_{i}$ when SR increases, however the maximum effect is located at $\mathrm{SR}=2$ and it is so low that it can not compensate the effect of the higher heat transfer losses. With SR higher than 2, both effects decrease leading to a $\eta_{i}$ diminution of $1.2 \%$ at $\mathrm{SR}=2.95$ respect to $\mathrm{SR}=1.38(\Delta \mathrm{HT}$ effect $=-0.4 \%$ and $\Delta$ RoHR effect $=-0.8 \%$ ). At this k-point, it would be interesting to explore SR below 1.38 to improve $\eta_{i}$, however it was not possible with the available engine hardware.

Taking into account the previous analysis, it is clear that swirl effect on $\eta_{i}$ depends heavily on the operating conditions. However, some global statements can be made if load and engine speed sweeps are considered. On the one hand, when SR increases, the efficiency reduction due to the higher heat transfer (column 6 in Table 4) diminished with load. This has also been observed at $2000 \mathrm{rpm}$ k-points (see Table 3), althougth for the sake of brevity they have not been presented. On the other hand, increasing swirl enhances the initial combustion stages but later tends to worsen the combustion process limiting the RoHR peak. The resulting effect of these RoHR changes on $\eta_{i}$ is possitive at intermediate SR, but tends to diminish with both load and speed. As a consequence of the combination of heat transfer and combustion changes, a maximum $\eta_{i}$ is found at a certain SR in all k-points, being located at lower SR when the engine speed increases.

The benefits observed in some k-points at intermediate SR in terms of gross indicated efficiency do not lead to brake efficiency improvements (see Figure 4), mainly due to the increase of pumping losses. This term increased almost linearly when swirl ratio went up. As explained in the engine characteristics subsection, the way to increase swirl consists in closing the valve located upstream of the helical port. This increases the restriction to the intake air flow, which produces a pressure drop, making necessary a more closed VGT position to reach the required higher boost pressure and hence to get the same trapped mass in the cylinder as when it is open ( $\mathrm{SR}=1.38)$. As a consequence, pumping losses increased $0.9 \%$ at $1500 \_8,1.4 \%$ at $1500 \_14$ and $0.7 \%$ at 3000_14. Although this effect could be reduced by keeping constant the turbine position, this would diminish the intake pressure and the air flow, increasing the fuel to air ratio and thus changing completely the in-cylinder conditions and combustion process.

For the sake of brevity, auxiliary and friction losses have not been plotted separately but the sum of both terms did not show significant variations in the swirl sweep. Auxiliary losses, which depend on fuel, cooling and oil pumps 
power [30], did not change since the engine speed, injection pressure, coolant mass flow and oil pressure were constant. On the other hand, oil temperature was kept constant, thus no important effect on engine friction took place when swirl increased.

According to the performed analysis, brake efficiency variations were governed by gross indicated efficiency and pumping losses. Since pumping losses and gross indicated efficiency in most cases affected brake efficiency negatively, the global trend in all the k-points was to decrease. It was found that only in one operating condition, 1500_14 and $\mathrm{SR}=2$, increasing the SR led to higher brake efficiency. At this point, gross indicated efficiency was $0.7 \%$ better than the reference point due to the better mixing process, while pumping losses were not as important as for highest swirl level $(-0.2 \%)$. The combination of these factors led to a brake efficiency $0.4 \%$ higher than the one at lowest swirl level.

\subsection{Heat transfer}

The analysis performed in the previous section regarding the instantaneous evolution of heat transfer in the chamber is extended here through a deeper analysis. Since changes in auxiliary and friction losses, responsible for a portion of the heat transfer to coolant and oil, were almost negligible, the study will be focused on the heat transfer to the combustion chamber and port walls.

Experimental heat transfer to coolant and oil is presented in Figure 11, where it can be seen that both terms increased when SR increased (specially the coolant). Moreover, no clear difference in the behavior of the three k-points can be observed neither in heat rejection to coolant nor to oil.

In the case of the coolant heat transfer, it is shown that the mean value increases between $1.2 \%$ and $1.5 \%$ of the fuel energy (depending on the k-point) when SR went from the minimum to the maximum value. If a detailed analysis of the coolant heat rejection sources is performed, main sub-terms involved are heat rejection to cylinder-head, cylinder liner and ports. The modeled variation of these terms is plotted in Figure 12. As shown, both heat transfer to cylinder-head and cylinder liner increased with swirl about $0.6 \%$ of the fuel energy (each one) in all the k-points, as a consequence of the changes in air velocity and in-cylinder conditions already described. On the other hand, heat transfer to ports rose about $0.7 \%$ at high load cases due to the longer combustion and it decreased $-0.3 \%$ (only at the highest SR) at 1500_8 because of the shorter combustion duration.

Regarding HT to oil in Figure 11, no significant variation can be seen up to $\mathrm{SR}=2.5$, moreover only a small rise of about $0.5 \%$ of the fuel energy was obtained at the highest SR at 1500_8 and 1500_14. Although the repetitivity of the tests is high, the experimental determination of this term is problably in the limit of what can be measured. Main components of this term are friction, which hardly changed, and heat transfer to piston, which is plotted at the bottom 
of Figure 12. Modeled piston HT increased almost linearly with swirl, reaching a maximum variation at the highest SR level ranging between $0.8 \%$ and $1 \%$ of the fuel energy at different k-points. If this change is compared with the experimental measurements (variation lower to $0.5 \%$ ), it is possible to say that the model slightly overestimates the effect of swirl on the heat transfer to piston.

\subsection{Exhaust gases sensible enthalpy}

Another important term in the external balance is the exhaust gases net sensible enthalpy, shown in the top part of Figure 13. This enthalpy was calculated downstream of the turbine and in the swirl study it was only affected by the change of exhaust temperature because the intake flow and temperature were kept constant. Thus, at 1500_8, where the combustion got shorter and the exhaust gases got cooler in the SR sweep (bottom plot of Figure 13), this term decreased $-0.8 \%$. Since the combustion duration increased with swirl in the other 2 high load k-points, exhaust temperatures were higher and sensible enthalpy rose about $0.2 \%$.

\subsection{Other terms}

To conclude the thermal analysis there are some remaining terms involved in the experimental external balance: heat transfer in the intercooler and the miscellanea term $\dot{Q}_{m i s c}$. Their variation with swirl rate change is shown in Figure 14.

Regarding heat transfer in the intercooler, a slightly increment was observed during the swirl sweep due to the higher boost pressure required to get the same trapped mass when the swirl valve gets closed to increase swirl rate. To reach the higher pressure, the compressor work increases and, consequently, the temperature at the compressor outlet increases as well, being necessary a higher cooling power in the intercooler to mantain the same temperature in the intake manifold (always constant at $45^{\circ} \mathrm{C}$ ). Thus, this cooling power was $0.6 \%$ higher at the last swirl value at 3000_14, where the pressure increment was also higher $(0.2 \mathrm{bar})$, while it was about $0.3 \%$ greater in the $1500 \mathrm{rpm}$ cases (with a pressure increase of $50 \mathrm{mbar}$ ).

Finally, the last term to complete the GEB analysis is $\dot{Q}_{m i s c}$. As explained in the methodology section, this term includes some minor energy flows $\left(\dot{Q}_{e x t}, \dot{H}_{b b}, \dot{H}_{i c}\right.$ and $\left.\dot{Q}_{f}\right)$ as well as the energy unbalance due to experimental uncertainties. Due to the small variation of these terms during the swirl sweeps, variation of $\dot{Q}_{m i s c}$ should be mainly due to uncertainties. As shown in the bottom part of Figure 14, changes in this term have a mean value about $0.2 \%$ in all the cases (a maximum value lower to $1 \%$ ) althougt its repetitivity shows a wide variation range of about $1 \%$ of the fuel energy. Taking into account that the unbalance includes all the experimental uncertainties during the measurement of 
the fuel mass, fluids flow rates and temperature drops, it can be considered a suitable result to validate the experimental measurements.

\section{Conclusions}

A comprehensive analysis of the GEB, allowed determining the effect of swirl increase on engine efficiency and losses. The main conclusions of this work are:

- Swirl rate increment did not always affect $\eta_{i}$ in the same way, and its global impact depends on the operating conditions and the swirl level. There are two main factors affecting this efficiency: heat transfer and changes in the RoHR shape.

- Heat transfer was always higher when swirl increased because of the higher air tangential velocity and the consequent major heat transfer coefficient at high swirl ratios. However, the heat rejection difference between extreme swirl levels got lower when load was increased.

- RoHR has different effect depending on the operating conditions and the combination of the phenomena occurring during the RoHR evolution. During the first combustion stage, RoHR was always enhanced when swirl increased due to the better mixture process promoted by the higher air velocity at high swirl levels. However, the maximum combustion rate was affected in different ways depending on load and engine speed. At low load, the RoHR peak got higher when swirl increased up to $\mathrm{SR}=2$, unlike the worsening effect seen when increasing SR at high load. This deterioration could be due to the interaction between injection sprays due to the high swirl motion and/or the flame displacement towards the squish region produced by this high motion, although further analysis with CFD would be necessary to confirm this point. This combustion degradation was compensated by the enhancement of the RoHR during the main combustion rise at 1500_14, but at 3000_14 the negative impact of the peak deterioration was higher than the benefit achieved during the first stage.

- Combination of heat transfer and RoHR effects ( $\Delta \mathrm{HT}$ and $\Delta$ RoHR respectively) led to a maximum $\eta_{i}$ at $1500 \_8$ at $\mathrm{SR}=2.5$, where the $\Delta \mathrm{RoHR}$ effect (1.7\%) is higher than the $\Delta \mathrm{HT}$ effect (-0.5\%). Similar results are observed at 1500_14 with a maximum $\eta_{i}$ also located at $\mathrm{SR}=2.5$, where the $\Delta \mathrm{RoHR}$ and the $\Delta \mathrm{HT}$ are $1.1 \%$ and $-0.3 \%$ respectively. Finally, no better $\eta_{i}$ was achieved at 3000_14 in the swirl sweep, where both $\Delta$ RoHR and $\Delta H T$ tend to decreased $-0.8 \%$ and $-0.4 \%$ respectively. As a global trend, the SR value where the maximum $\eta_{i}$ is found is lower when the engine speed increases.

- Brake efficiency variations were controlled by $\eta_{i}$ and pumping losses. Having in mind the previous conclusions and taking into account that pumping losses always increase when swirl gets higher, the global trend of brake efficiency in almost all the k-points was to decrease (between $-0.9 \%$ and -1.4\%). Only at 1500_14 a higher $\eta_{b}$ 
was found at $\mathrm{SR}=2$ because gross indicated efficiency was better than the reference point due to the enhanced mixing process, while pumping losses only showed a slight worsening with respect to lower SR.

- Heat rejection to coolant increases about 1.3\% in all the cases when SR augmented. This heat transfer increase is due to the higher heat transfer to cylinder, cylinder-head and ports that increase about $0.6 \%$.

- Exhaust gases sensible enthalpy, which depends on the exhaust gases temperature, decreased $-0.8 \%$ at low load (1500_8) with swirl, where the exhaust temperature was lower due to the shorter combustion duration. In the high load k-points (1500_14 and 3000_14), exhaust temperatures were higher (longer combustion duration) and thus, sensible enthalpy rose about $0.2 \%$ when swirl increased.

- Heat transfer in the intercooler increased about $0.5 \%$ with swirl due to the changes in the intake pressure.

\section{Acknowledgements}

The support of GM Global R\&D and the Spanish Ministry of Economy and Competitiveness (TRA2013-41348-R) is greatly acknowledged. 


\section{References}

[1] B. Mohan, W. Yang, S. K. Chou, Fuel injection strategies for performance improvement and emissions reduction in compression ignition engines-A review, Renewable and Sustainable Energy Reviews 28 (2013) 664-676. doi:10.1016/j.rser.2013.08.051.

[2] A. K. Agarwal, D. K. Srivastava, A. Dhar, R. K. Maurya, P. C. Shukla, A. P. Singh, Effect of fuel injection timing and pressure on combustion, emissions and performance characteristics of a single cylinder diesel engine, Fuel 111 (2013) 374-383. doi:10.1016/j.fuel.2013.03.016.

[3] S. D. Hiwase, S. Moorthy, H. Prasad, M. Dumpa, R. M. Metkar, Multidimensional Modeling of Direct Injection Diesel Engine with Split Multiple Stage Fuel Injections, Procedia Engineering 51 (2013) 670-675. doi:10.1016/j.proeng.2013.01.095.

[4] M. Canakci, Combustion characteristics of a DI-HCCI gasoline engine running at different boost pressures, Fuel 96 (2012) 546-555. doi:10.1016/j.fuel.2012.01.042.

[5] M. Pan, G. Shu, H. Wei, T. Zhu, Y. Liang, C. Liu, Effects of EGR, compression ratio and boost pressure on cyclic variation of PFI gasoline engine at WOT operation, Applied Thermal Engineering 64 (1-2) (2014) 491-498. doi:10.1016/j.applthermaleng.2013.11.013.

[6] G. Fontana, E. Galloni, Experimental analysis of a spark-ignition engine using exhaust gas recycle at WOT operation, Applied Energy 87 (7) (2010) 2187-2193. doi:10.1016/j.apenergy.2009.11.022.

[7] S. Verhelst, J. Demuynck, R. Sierens, P. Huyskens, Impact of variable valve timing on power, emissions and backfire of a bi-fuel hydrogen/gasoline engine, International Journal of Hydrogen Energy 35 (9) (2010) 4399-4408. doi:10.1016/j.ijhydene.2010.02.022.

[8] G. Fontana, E. Galloni, Variable valve timing for fuel economy improvement in a small spark-ignition engine, Applied Energy 86 (1) (2009) 96-105. doi:10.1016/j.apenergy.2008.04.009.

[9] F. Perini, P. C. Miles, R. D. Reitz, A comprehensive modeling study of in-cylinder fluid flows in a high-swirl, light-duty optical diesel engine, Computers \& Fluids 105 (2014) 113-124. doi:10.1016/j.compfluid.2014.09.011.

[10] S. Wei, F. Wang, X. Leng, X. Liu, K. Ji, Numerical analysis on the effect of swirl ratios on swirl chamber combustion system of DI diesel engines, Energy Conversion and Management 75 (2013) 184-190. doi:10.1016/j.enconman.2013.05.044.

[11] J. Benajes, R. Novella, D. De Lima, P. Tribotté, N. Quechon, P. Obernesser, V. Dugue, Analysis of the combustion process, pollutant emissions and efficiency of an innovative 2-stroke HSDI engine designed for automotive applications, Applied Thermal Engineering 58 (1-2) (2013) 181-193. doi:10.1016/j.applthermaleng.2013.03.050.

[12] P. Olmeda, J. Martín, R. Novella, R. C. no, An adapted heat transfer model for engines with tumble motion, Applied Energy 158 (2015) 190 - 202. doi:10.1016/j.apenergy.2015.08.051.

[13] T. Sandalcı, Y. Karagöz, Experimental investigation of the combustion characteristics, emissions and performance of hydrogen port fuel injection in a diesel engine, International Journal of Hydrogen Energy (2014) 1-10doi:10.1016/j.ijhydene.2014.09.044

[14] K. A. Sorate, P. V. Bhale, Biodiesel properties and automotive system compatibility issues, Renewable and Sustainable Energy Reviews 41 (2015) 777-798. doi:10.1016/j.rser.2014.08.079.

[15] J. Heywood, Internal Combustion Engines Fundamentals, McGraw-Hill, New York, 1988.

[16] Regulation (EU) No 333/2014 of the European Parliament and of the Council of 11 March 2014 amending Regulation (EC) No $443 / 2009$ to define the modalities for reaching the 2020 target to reduce CO2 emissions from new passenger cars, Official Journal of the European Union L103 Vol 57 (2014) 15-21.

[17] T. W. Ryan III, T. J. Callahan, Homogeneous Charge Compression Ignition of Diesel Fuel, SAE Technical paper 961160.

[18] R. Kiplimo, E. Tomita, N. Kawahara, S. Yokobe, Effects of spray impingement, injection parameters, and EGR on the combustion and emission characteristics of a PCCI diesel engine, Applied Thermal Engineering 37 (2012) 165-175. doi:10.1016/j.applthermaleng.2011.11.011.

[19] T. Köfer, M. Lamping, A. Kolbeck, T. Genz, S. Pischinger, B. H, D. Adolph, The potential of downsizing Diesel engines considering performance and emissions challenges, IMechE.

[20] M. Thirouard, P. Pacaud, Increasing Power Density in HSDI Engines as an Approach for Engine Downsizing, SAE Int. J. Engines 3 (2) (2010) 56-71.

[21] P. Tribotte, F. Ravet, V. Dugue, P. Obernesser, N. Quechon, J. Benajes, R. Novella, D. De Lima, Two Strokes Diesel Engine - Promising Solution to Reduce CO2 Emissions, Procedia - Social and Behavioral Sciences 48 (2012) 2295-2314. doi:10.1016/j.sbspro.2012.06.1202. 
[22] J. ichi Kawashima, Research on a variable swirl intake port for high-speed 4-valve \{DI $\}$ diesel engine, \{JSAE $\}$ Review 20 (3) (1999) 421 424. doi:http://dx.doi.org/10.1016/S0389-4304(99)00025-9.

[23] G. Woschni, A Universally Applicable Equation for the Instantaneous Heat Transfer Coefficient in the Internal Combustion Engine, SAE Technical Paper Series 670931.

[24] F. Payri, X. Margot, A. Gil, J. Martín, Computational Study of Heat Transfer to the Walls of a DI Diesel Engine, SAE Technical paper 2005-01-0210doi:10.4271/2005-01-0210.

[25] J. Benajes, S. Molina, J. M. Garcia, J. M. Riesco, The effect of swirl on combustion and exhaust emissions in heavy-duty diesel engines, Proceedings of the Institution of Mechanical Engineers, Part D: Journal of Automobile Engineering 218 (10) (2004) $1141-1148$. doi:10.1177/095440700421801009.

[26] P. C. Miles, The Influence of Swirl on HSDI Diesel Combustion at Moderate Speed and Load, SAE Technical Paper 2000-011829doi:10.4271/2000-01-1829.

[27] D. Choi, P. C. Miles, H. Yun, R. D. Reitz, A parametric study of low-temperature, late-injection combustion in a hsdi diesel engine, JSME International Journal Series B Fluids and Thermal Engineering 48 (4) (2005) 656-664. doi:10.1299/jsmeb.48.656.

[28] C. Abdul Gafoor, R. Gupta, Numerical investigation of piston bowl geometry and swirl ratio on emission from diesel engines, Energy Conversion and Management 101 (2015) 541-551. doi:10.1016/j.enconman.2015.06.007.

[29] B. Prasad, C. Sharma, T. Anand, R. Ravikrishna, High swirl-inducing piston bowls in small diesel engines for emission reduction, Applied Energy 88 (7) (2011) 2355-2367. doi:10.1016/j.apenergy.2010.12.068.

[30] F. Payri, P. Olmeda, J. Martín, R. Carreño, A New Tool to Perform Global Energy Balances in DI Diesel Engines, SAE Int. J. Enginesdoi:10.4271/2014-01-0665.

[31] F. Payri, J. Martín, A. García, R. Carreño, Experimental and Theoretical Analysis of the Energy Balance in a DI Diesel Engine, SAE Technical paper 2015-01-1651doi:10.4271/2015-01-1651.

[32] J. Benajes, P. Olmeda, J. Martín, R. Carreño, A new methodology for uncertainties characterization in combustion diagnosis and thermodynamic modelling, Applied Thermal Engineering 71 (2014) 389-399. doi:10.1016/j.applthermaleng.2014.07.010.

[33] F. Payri, P. Olmeda, J. Martín, A. García, A complete 0D thermodynamic predictive model for direct injection diesel engines, Applied Energy (88) (2011) 4632-4641. doi:10.1016/j.apenergy.2011.06.005.

[34] F. Payri, J. Galindo, J. Martín, F. Arnau, A Simple Model for Predicting the Trapped Mass in a DI Diesel Engine, SAE Technical Paper 2007-01-0494doi:10.1016/j.applthermaleng.2005.10.021.

[35] M. Lapuerta, O. Armas, J. J. Hernández, Diagnosis of DI Diesel combustion from in-cylinder pressure signal by estimation of mean thermodynamic properties of the gas, Applied Thermal Engineering c (1999) 513-529.

[36] F. Payri, S. Molina, J. Martín, O. Armas, Influence of measurement errors and estimated parameters on combustion diagnosis, Applied Thermal Engineering 26 (2-3) (2006) 226-236. doi:10.1016/j.applthermaleng.2005.05.006.

[37] A. J. Torregrosa, P. Olmeda, J. Martín, C. Romero, A Tool for Predicting the Thermal Performance of a Diesel Engine, Heat Transfer Engineering 32 (10) (2011) 891-904.

[38] J. Benajes, R. Novella, D. De Lima, P. Tribotte, Analysis of combustion concepts in a newly designed two-stroke high-speed direct injection compression ignition engine, International Journal of Engine Research 16 (1, SI) (2015) 52-67. doi:10.1177/1468087414562867.

[39] J. Benajes, J. Martín, R. Novella, K. Thein, Understanding the performance of the multiple injection gasoline partially premixed combustion concept implemented in a 2-Stroke high speed direct injection compression ignition engine, Applied Energy 161 (2016) 465-475. doi:10.1016/j.apenergy.2015.10.034.

[40] A. Torregrosa, P. Olmeda, B. Degraeuwe, M. Reyes, A concise wall temperature model for DI Diesel engines, Applied Thermal Engineering 26 (11-12) (2006) 1320-1327. doi:10.1016/j.applthermaleng.2005.10.021.

[41] J. Benajes, J. Martín, A. García, D. Villalta, A. Warey, In-cylinder soot radiation heat transfer in direct-injection diesel engines, Energy Conversion and Management 106 (2015) 414-427. doi:10.1016/j.enconman.2015.09.059.

[42] M. E. Mccracken, J. Abraham, Swirl-Spray Interactions in a Diesel Engine 2001 (724). doi:10.4271/2001-01-0996. 
[43] J. Morena, A. Vassallo, R. C. Peterson, V. Gopalakrishan, J. Gao, Influence of Swirl Ratio On Combustion System Performance of a 0.4L Single-Cylinder Diesel Engine, THIESEL 2014 Conference on Thermo-and Fluid Dynamics Processes in Direct Injection Engines.

[44] F. Weberbauer, M. Rauscher, A. Kulzer, M. Knopf, M. Bargende, Generally applicate split of losses for new combustion concepts, MTZ worldwide 66 (2) (2005) 17-19. doi:10.1007/BF03227736. 


\section{Figures}

Figure 1. Experimental set-up

Figure 2. Global Energy Balance scheme

Figure 3. External GEB for the reference k-points $(\mathrm{SR}=1.38)$

Figure 4. Variation of experimental brake efficiency parameters with SR

Figure 5. Experimental instantaneous in-cylinder pressure and RoHR at 1500_8

Figure 6. Experimental instantaneous in-cylinder pressure and RoHR at 1500_14

Figure 7. Experimental instantaneous in-cylinder pressure and RoHR at 3000_14

Figure 8. Variation of combustion duration, delay time and CA90 with SR

Figure 9. Modeled instantaneous HT in the chamber and gas temperature at the three k-points

Figure 10. Split of losses study on gross indicated efficiency

Figure 11. Variation of experimental HT to coolant and oil with SR

Figure 12. Variation of modeled HT in chamber and ports with SR

Figure 13. Variation of experimental exhaust gases sensible enthalpy and exhaust temperature with SR

Figure 14. Variation of experimental heat transfer to intercooler and miscellanea term with SR 


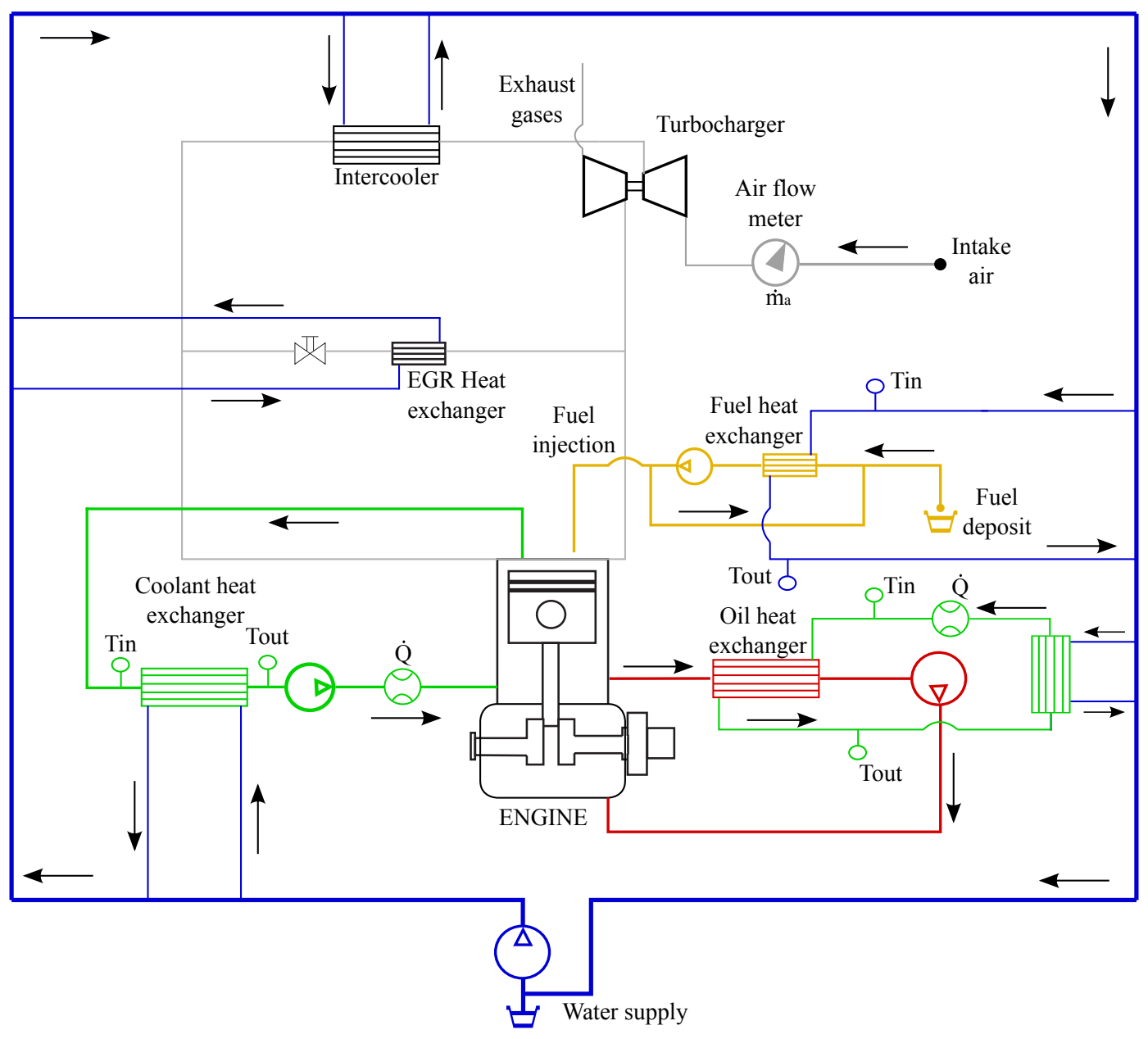

Figure 1: Experimental set-up 


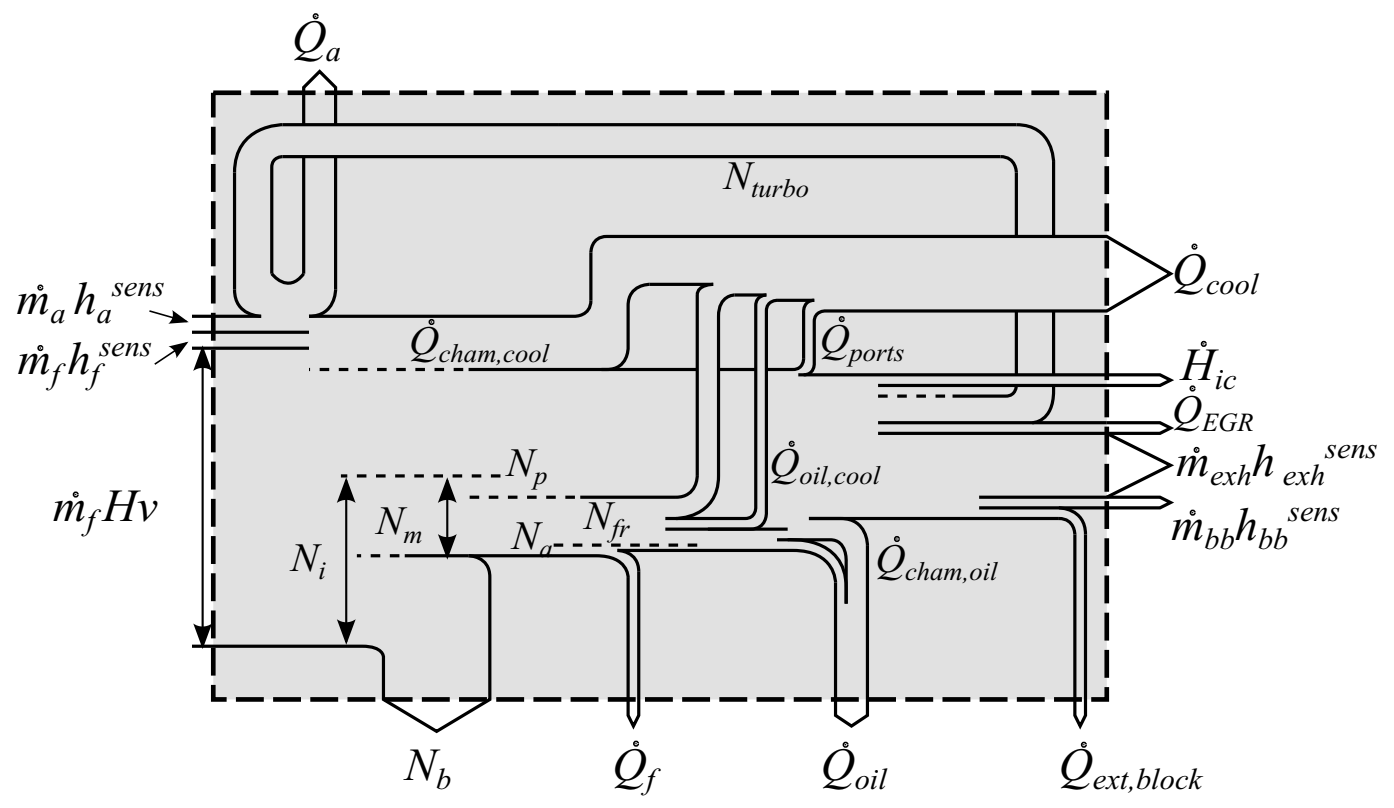

Figure 2: Global Energy Balance scheme 


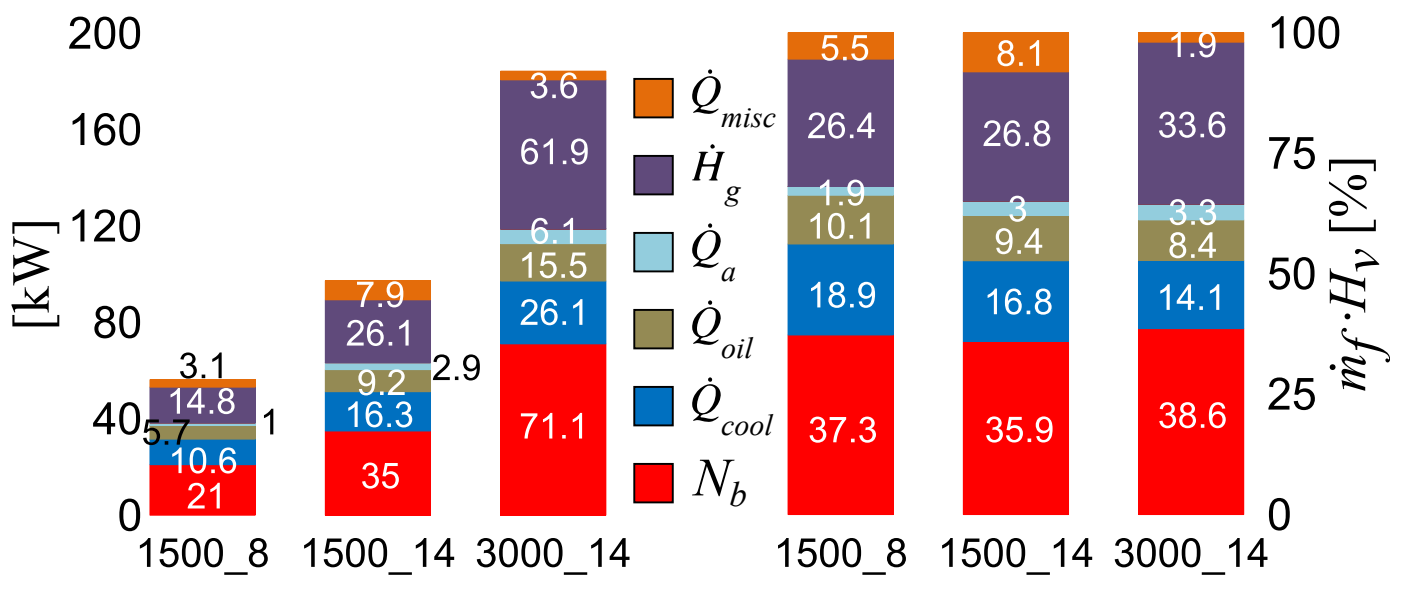

Figure 3: External GEB for the reference k-points $(\mathrm{SR}=1.38)$ 


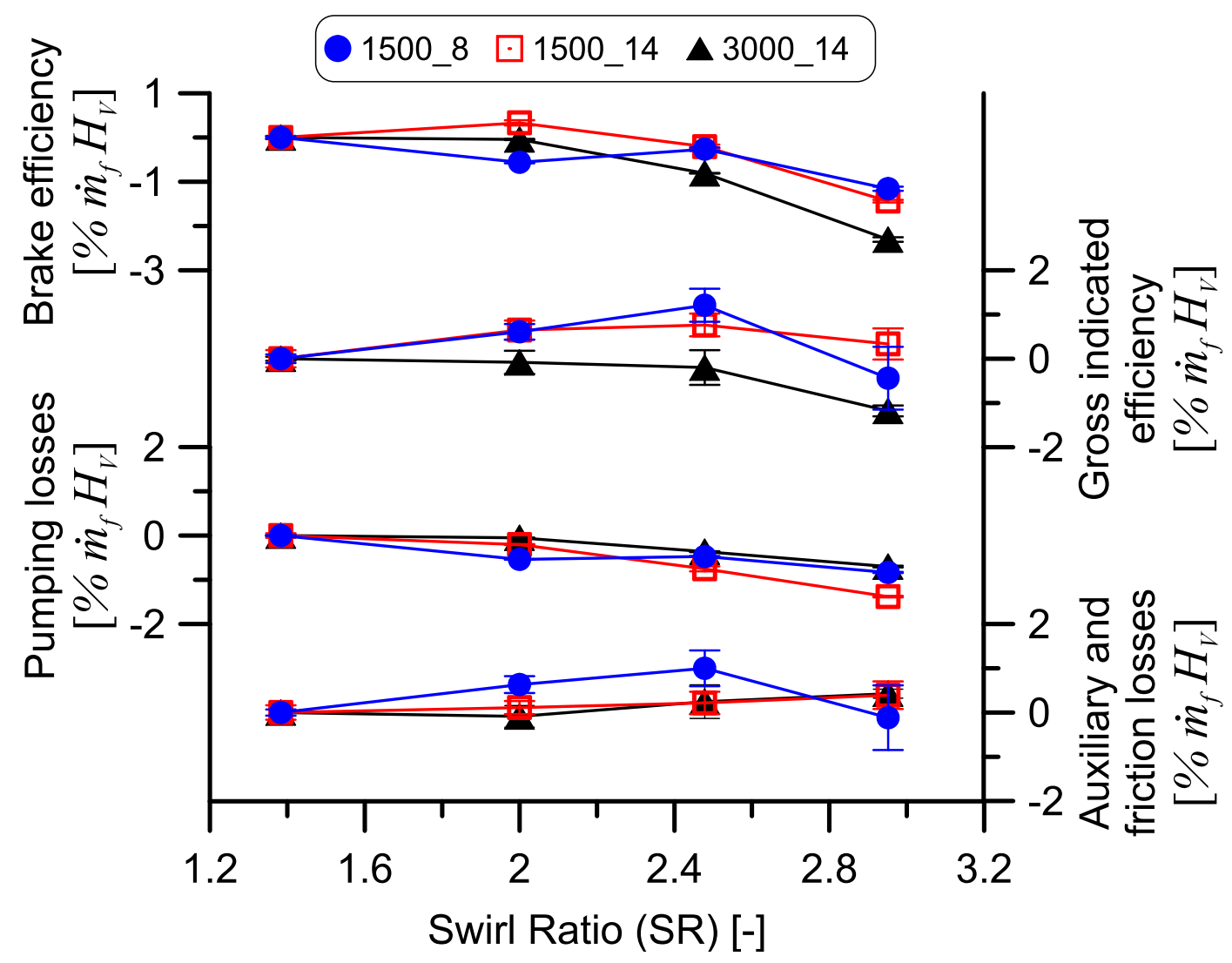

Figure 4: Variation of experimental brake efficiency parameters with SR 


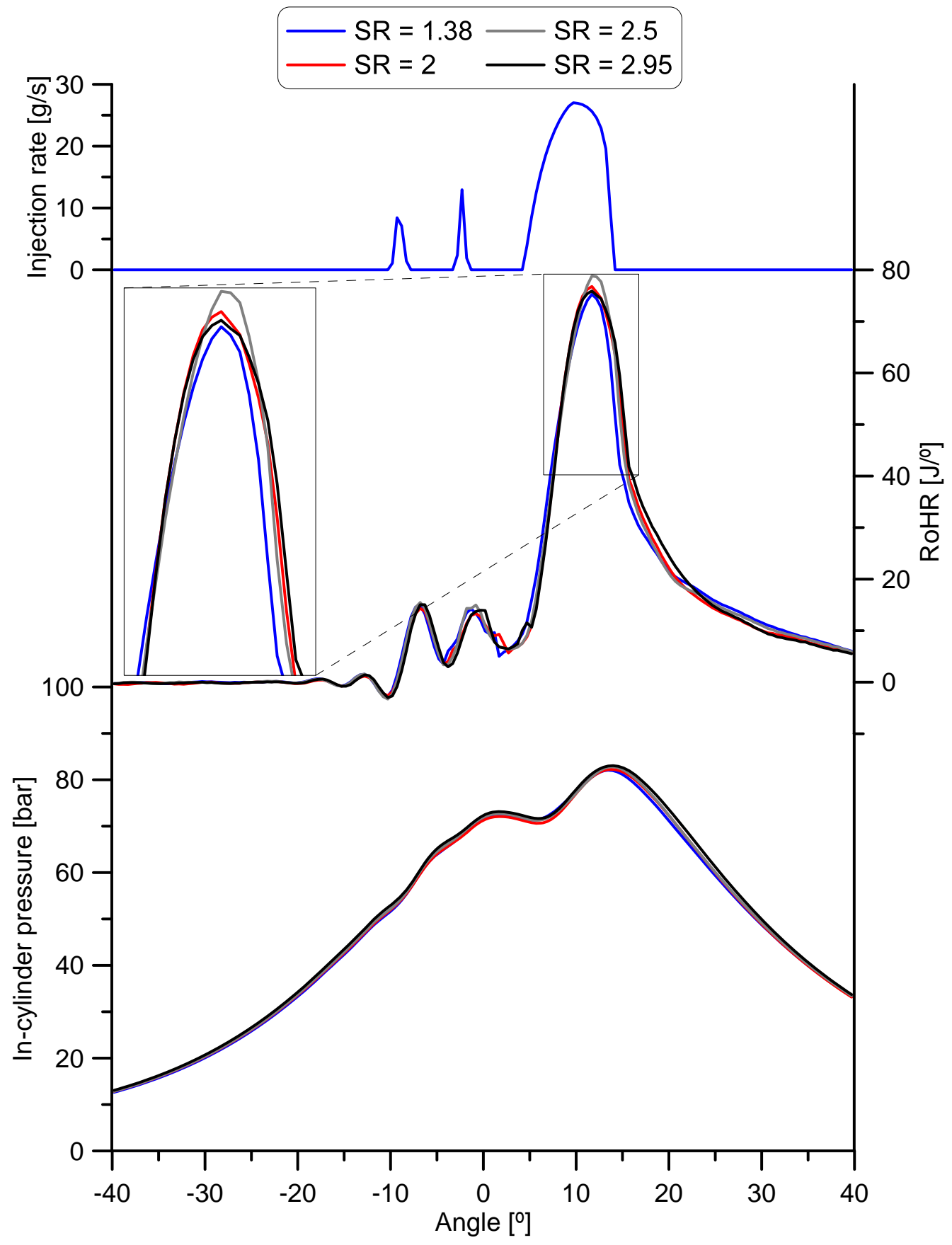

Figure 5: Experimental instantaneous in-cylinder pressure and RoHR at 1500_8 


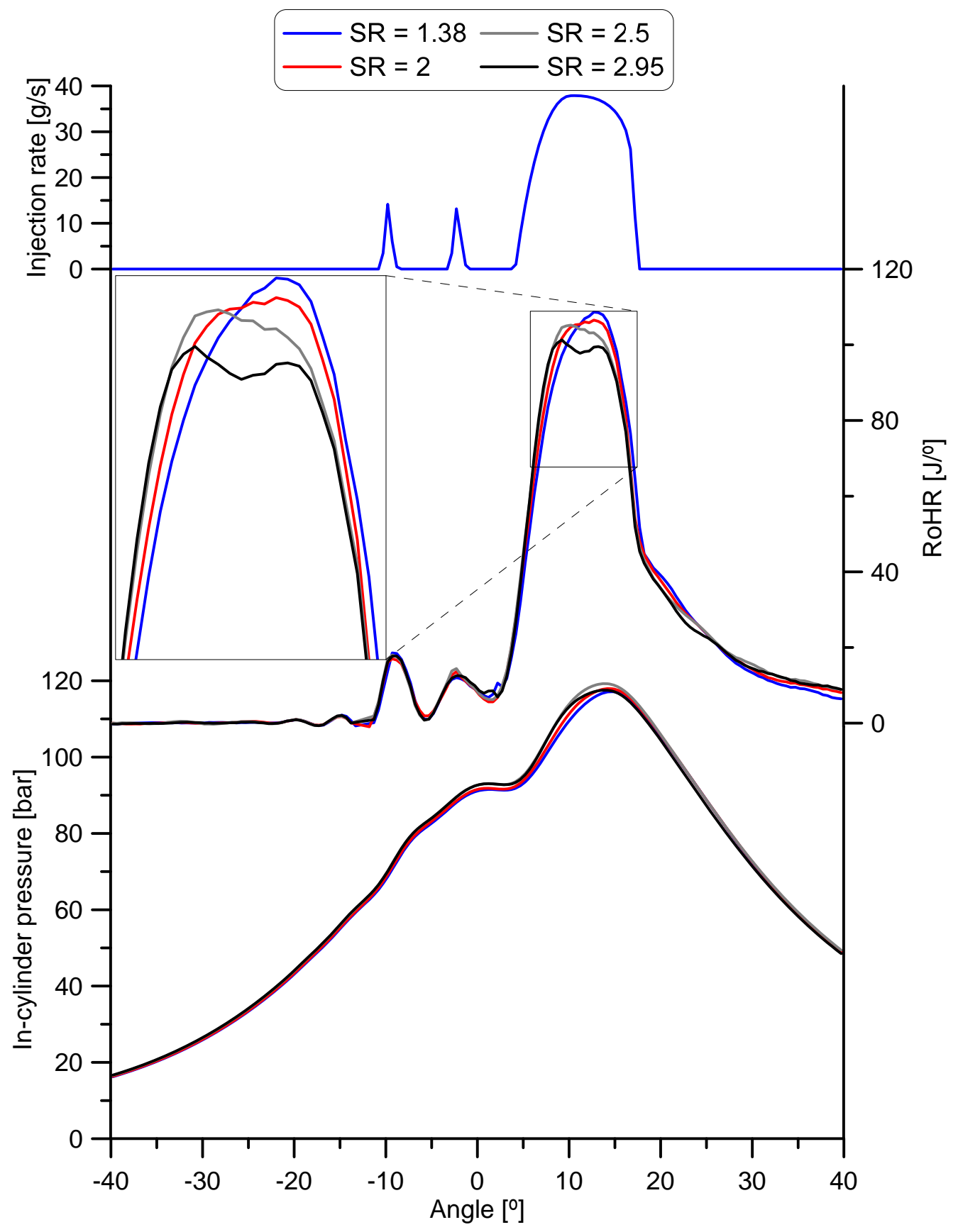

Figure 6: Experimental instantaneous in-cylinder pressure and RoHR at 1500_14 


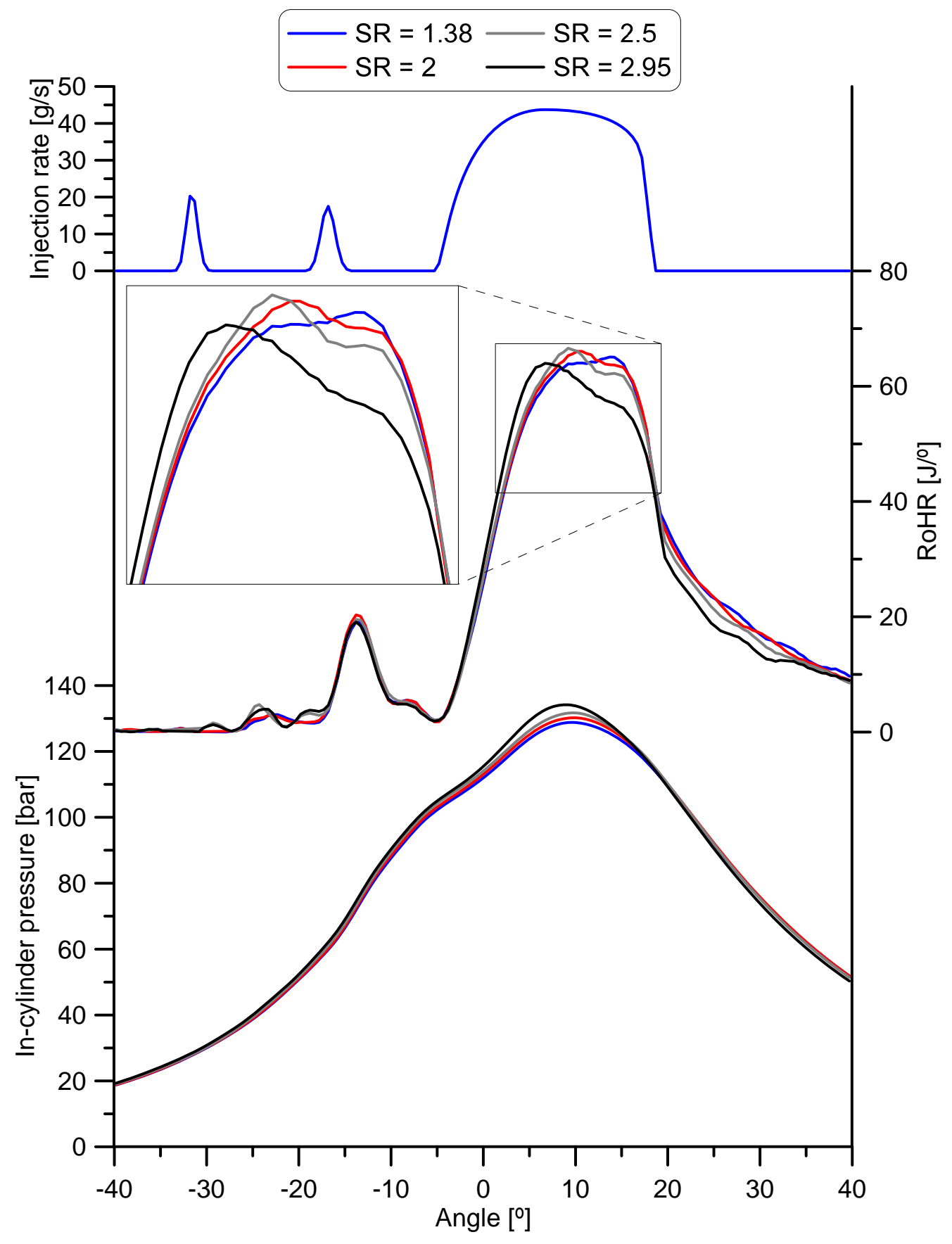

Figure 7: Experimental instantaneous in-cylinder pressure and RoHR at 3000_14 


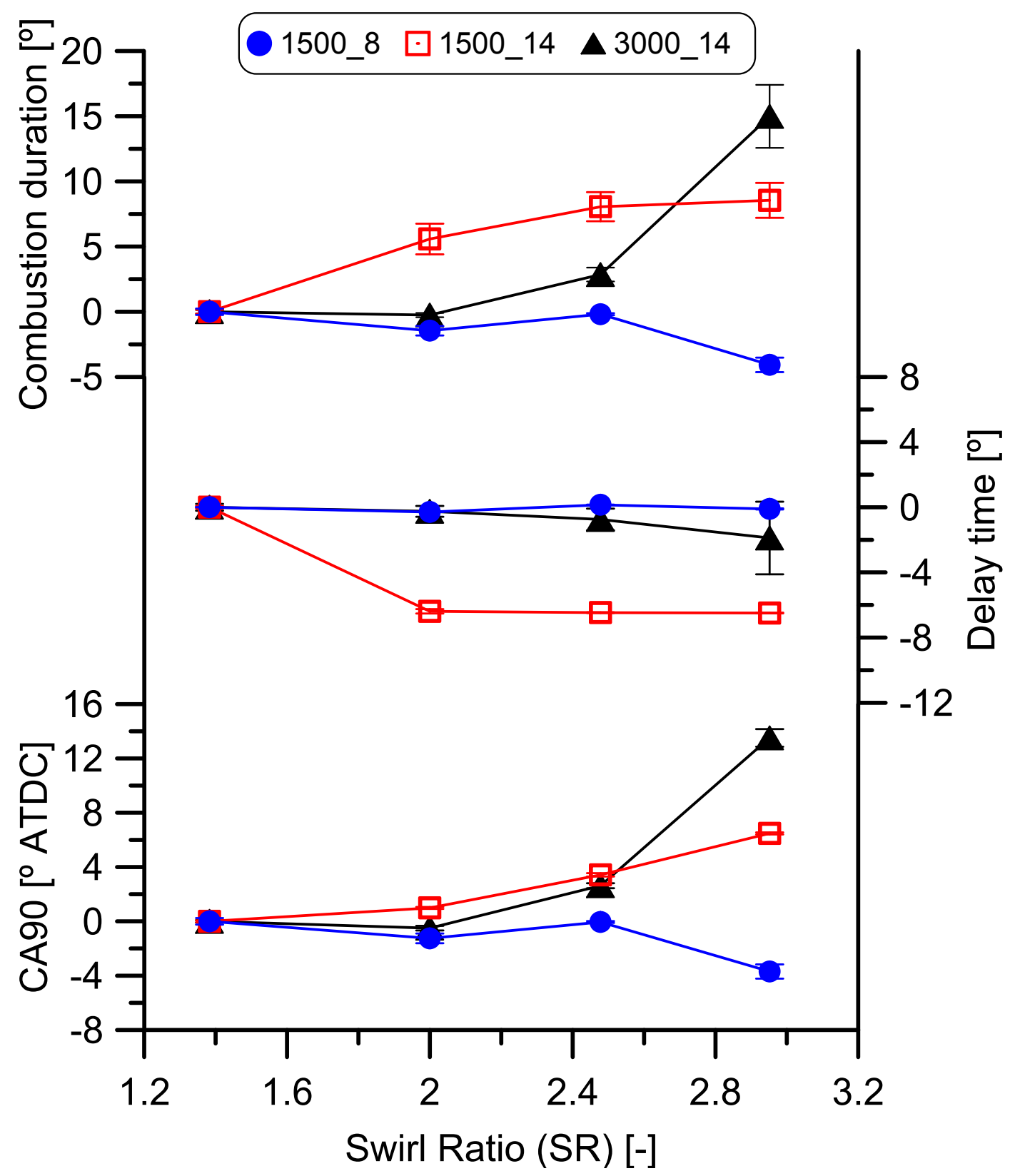

Figure 8: Variation of combustion duration, delay time and CA90 with SR 


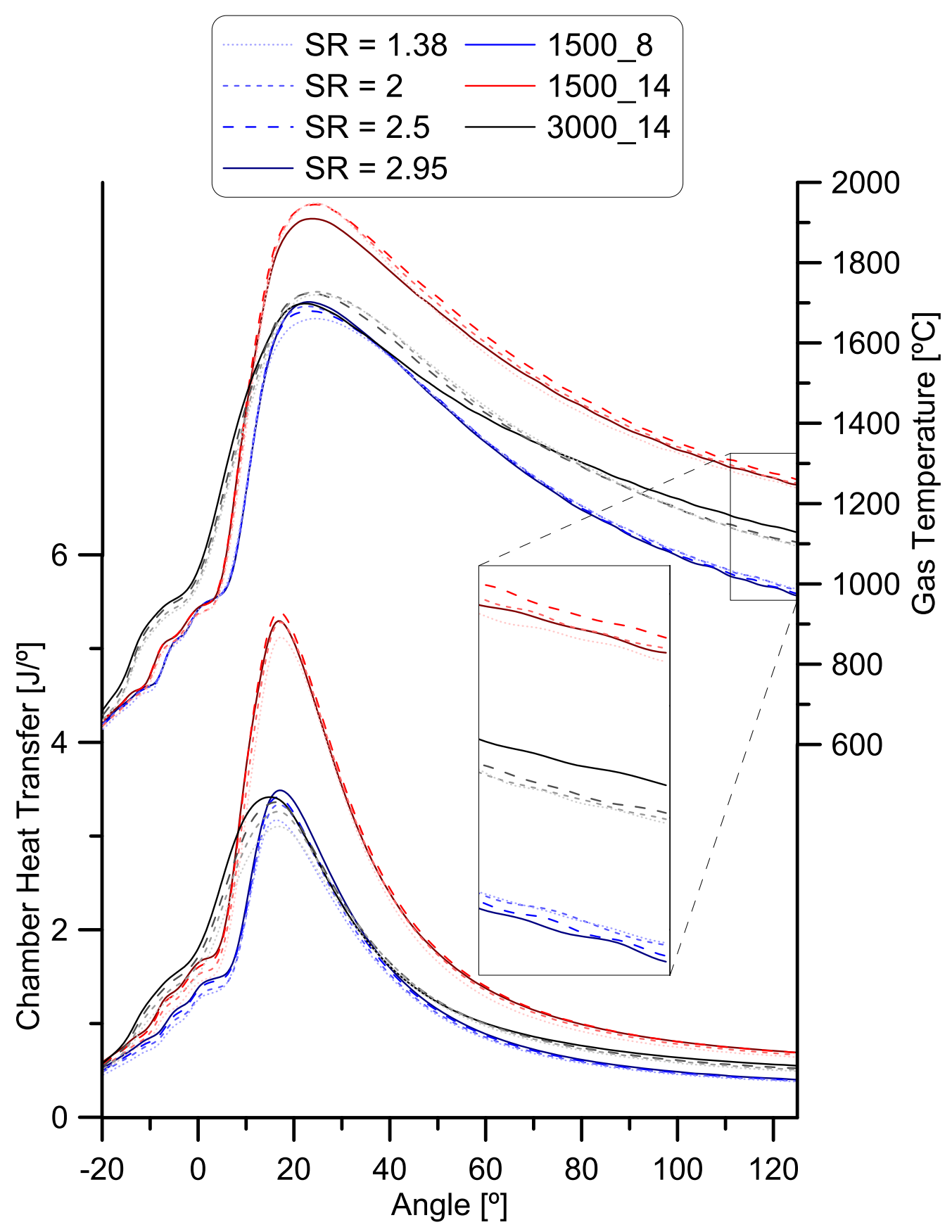

Figure 9: Modeled instantaneous HT in the chamber and gas mean temperature 


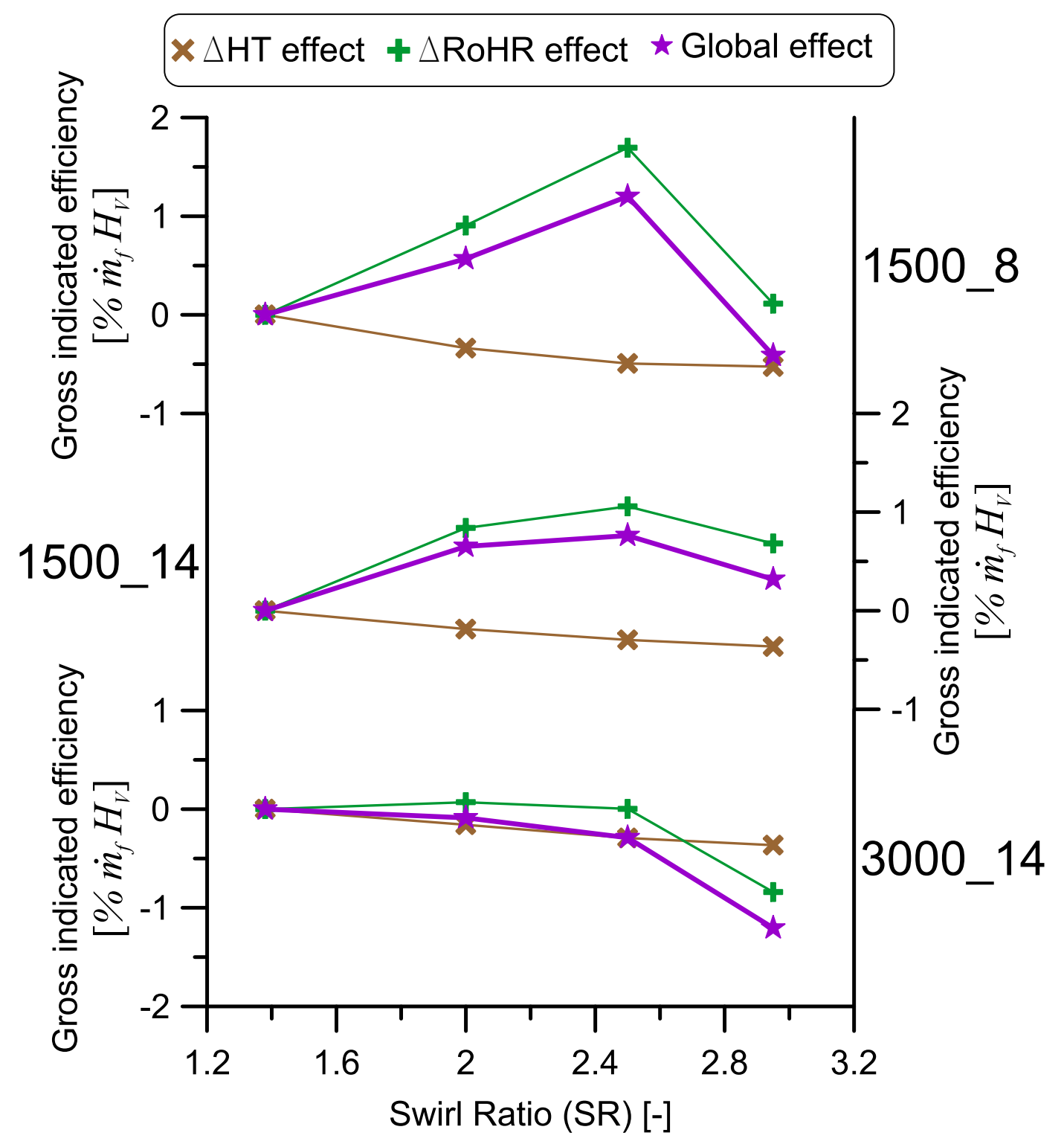

Figure 10: Split of losses study on gross indicated efficiency 


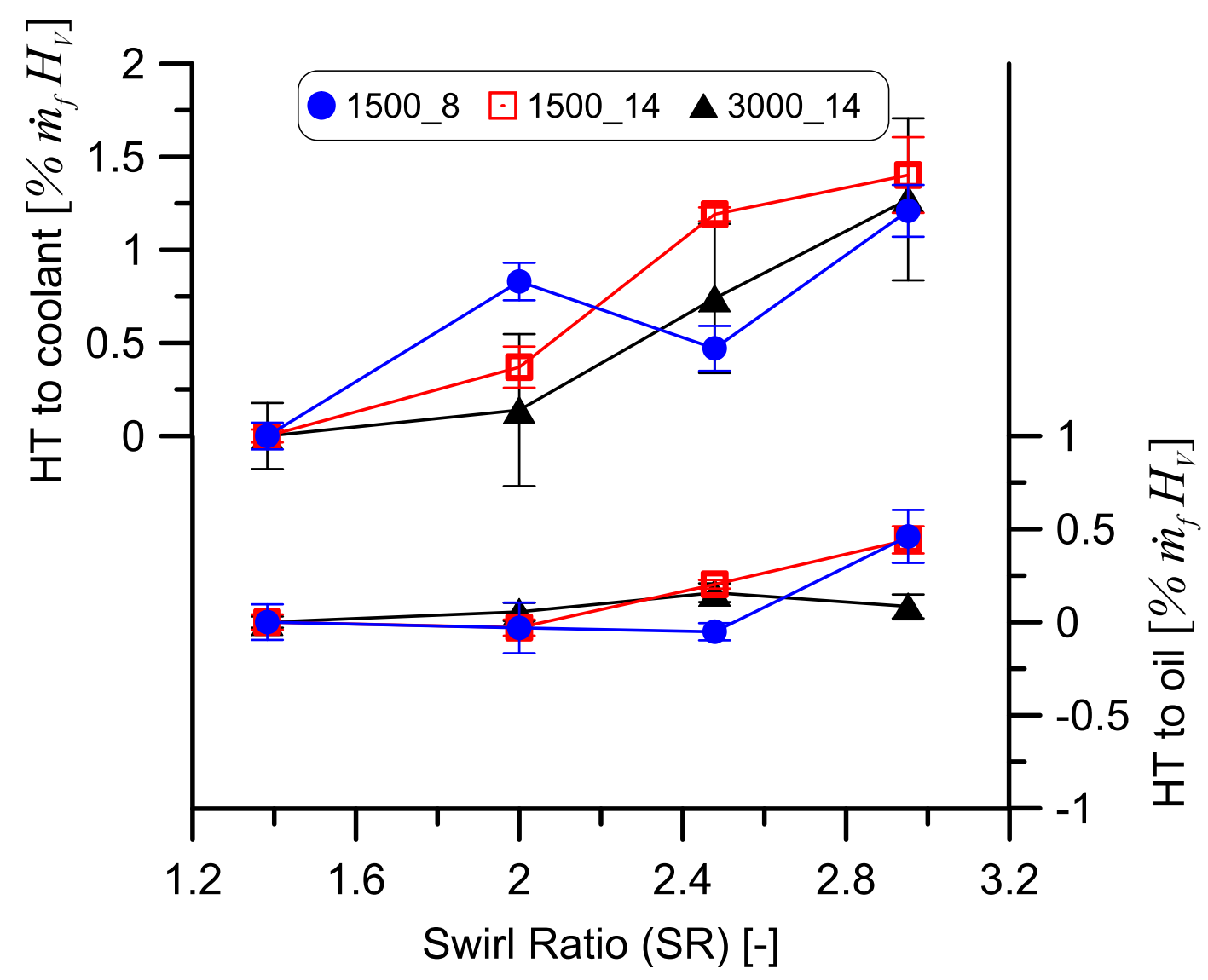

Figure 11: Variation of experimental HT to coolant and oil with SR 


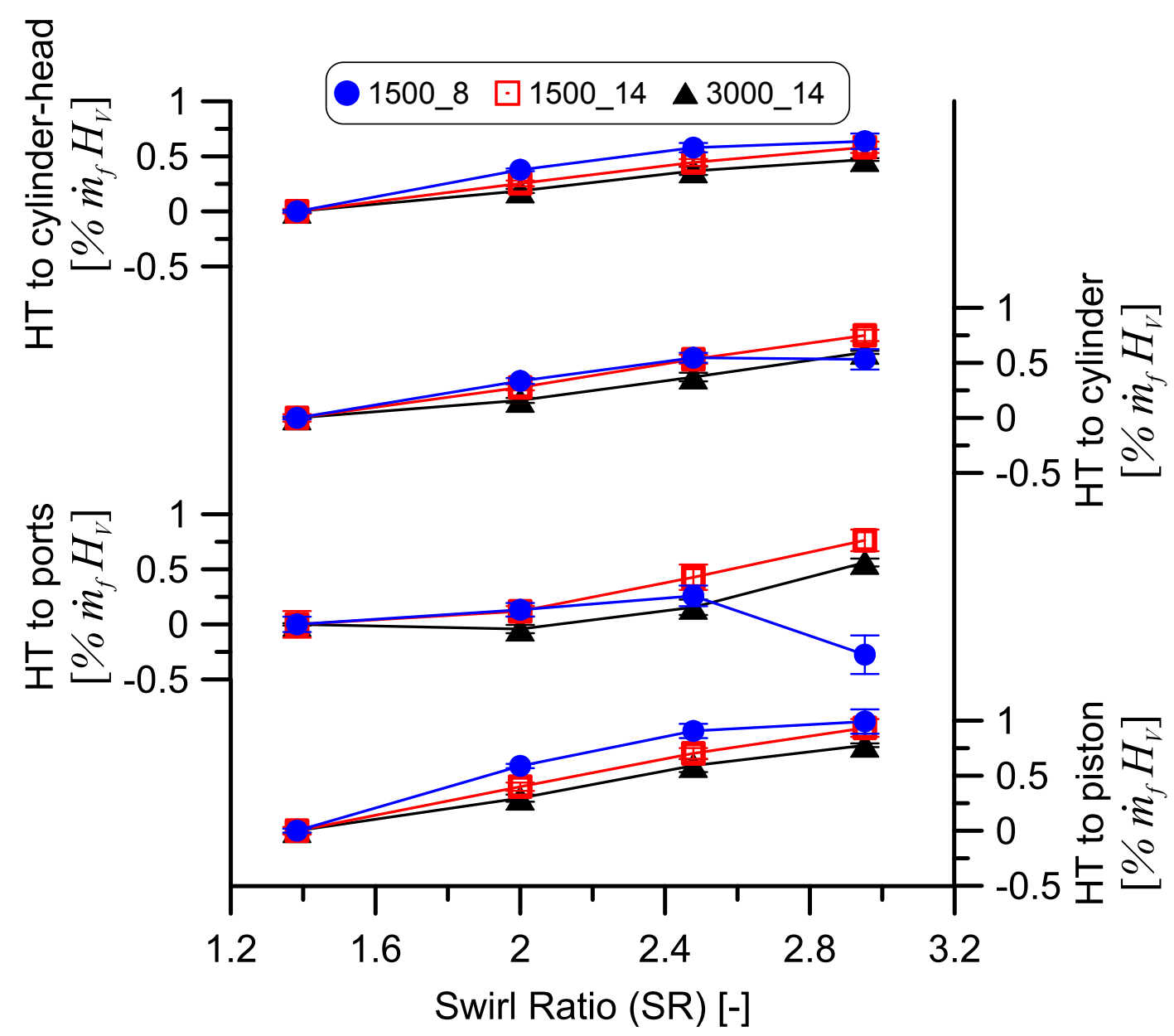

Figure 12: Variation of modeled HT in chamber and ports with SR 


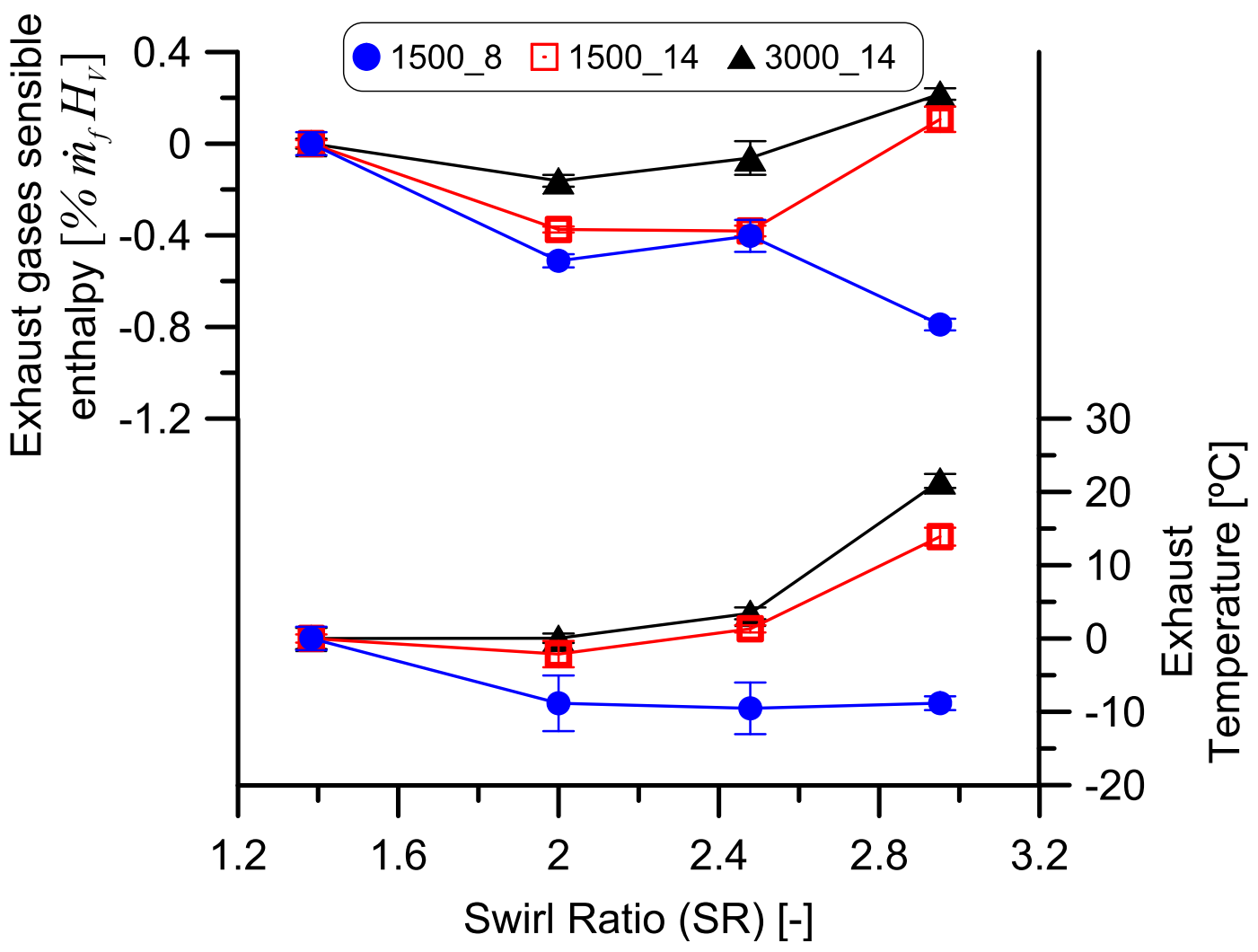

Figure 13: Variation of experimental exhaust gases sensible enthalpy and exhaust temperature with SR 


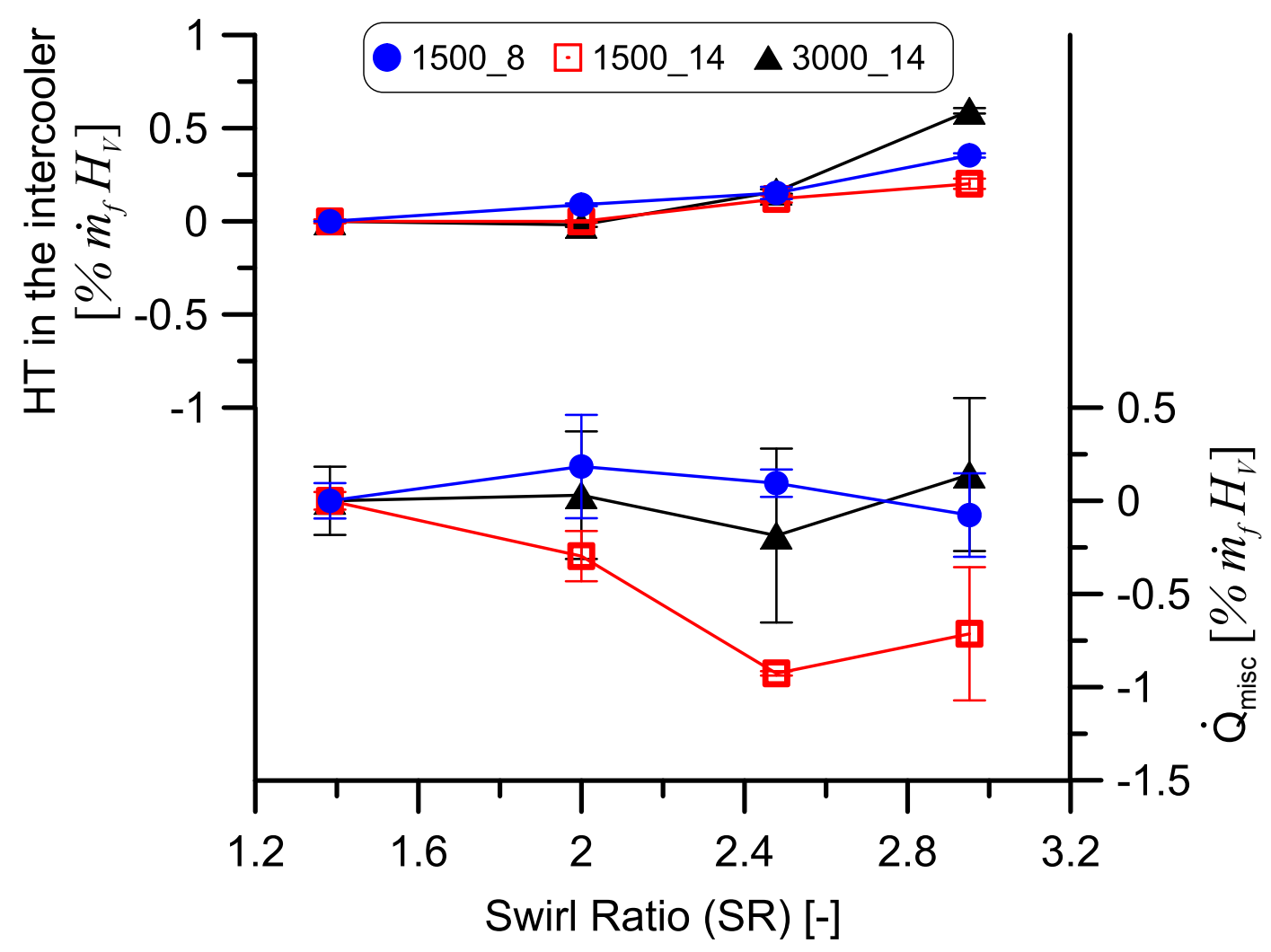

Figure 14: Variation of experimental HT to intercooler and miscellanea term with swirl ratio 


\section{Tables}

Table 1. Engine technical data

Table 2. Test cell instrumentation

Table 3. Measured operational k-points

Table 4. Split of losses study in gross indicated efficiency 
Table 1: Engine technical data

\begin{tabular}{ll}
\hline Cylinder & 4 in-line \\
Stroke & $90.4 \mathrm{~mm}$ \\
Bore & $82 \mathrm{~mm}$ \\
Geometric CR & $17.5: 1$ \\
Number of valves/cylinder & 4 \\
Air Management & Turbocharged \\
Maximum power & $110 \mathrm{~kW} @ 4000 \mathrm{rpm}$ \\
Maximum torque & $315 \mathrm{Nm} @ 2000 \mathrm{rpm}$ \\
Cycle & Diesel \\
Injection & Common rail \\
Swirl ratio variation & $1.38-2.95$ \\
\hline
\end{tabular}


Table 2: Test cell instrumentation

\begin{tabular}{ll} 
Variable & Equipment \\
\hline Cylinder pressure & Kistler 6125C \\
Speed & Dynamometer \\
Torque & Dynamometer \\
Air mass flow & AVL Flowsonix Air \\
Fuel mass flow & AVL 733S Fuel meter \\
Control fluids temperature & K-type thermocouples \\
GEB fluids temperatures & PT100 Thermoresistances \\
Material walls temperature & K-type thermocouples \\
Mean pressure & Kistler Piezoresistive Pressure Transmitters \\
Gases analysis & Horiba Mexa 7100 DEGR \\
Coolant flow rate & Krohne 4010 Optiflux \\
Oil cooler water flow rate & Yoko Admag AE2018MG Isoil M8500 \\
EGR cooler water flow rate & Krohne 4010 Optiflux \\
\hline
\end{tabular}


Table 3: Measured operational k-points

\begin{tabular}{ccc|cccccc}
$\begin{array}{c}\text { Speed } \\
{[\mathrm{rpm}]}\end{array}$ & $\begin{array}{c}\text { BMEP } \\
{[\mathrm{bar}]}\end{array}$ & $\begin{array}{c}\text { SR } \\
{[-]}\end{array}$ & $\begin{array}{c}\text { Boost pressure } \\
{[\mathrm{b} a \mathrm{r}]}\end{array}$ & $\begin{array}{c}\text { Air mass flow } \\
{[\mathrm{g} / \mathrm{s}]}\end{array}$ & $\begin{array}{c}\text { EGR } \\
{[\%]}\end{array}$ & $\begin{array}{c}\text { Rail pressure } \\
{[\mathrm{b} \text { [r] }]}\end{array}$ & $\begin{array}{c}\text { SOE Main } \\
{[\mathrm{deg} \text { ATDC] }}\end{array}$ & $\begin{array}{c}\text { Fuel quantity Main } \\
{[\mathrm{mg} / \mathrm{cc}]}\end{array}$ \\
\hline $\mathbf{1 5 0 0}$ & $\mathbf{8}$ & $\mathbf{1 . 3 8} / \mathbf{2 . 9 5}$ & $\mathbf{1 . 3 3} / \mathbf{1 . 3 8}$ & $\mathbf{2 9 . 8}$ & $\mathbf{0}$ & $\mathbf{7 5 0}$ & $\mathbf{0 . 8} / \mathbf{1 . 4}$ & $\mathbf{2 3 . 5}$ \\
$\mathbf{1 5 0 0}$ & $\mathbf{1 4}$ & $\mathbf{1 . 3 8} / \mathbf{2 . 9 5}$ & $\mathbf{1 . 7 3} / \mathbf{1 . 7 8}$ & $\mathbf{3 8 . 5}$ & $\mathbf{0}$ & $\mathbf{1 0 5 0}$ & $\mathbf{0 . 1 5} / \mathbf{0 . 1}$ & $\mathbf{4 2 . 8}$ \\
2000 & 2 & $1.38 / 2.95$ & $1.17 / 1.23$ & 38.8 & 0 & 450 & $0.2 / 0.7$ & 6.8 \\
2000 & 5 & $1.38 / 2.95$ & $1.36 / 1.44$ & 44.0 & 0 & 650 & $-1.2 /-0.4$ & 14.7 \\
2000 & 15 & $1.38 / 2.95$ & $2.29 / 2.46$ & 72.3 & 0 & 1250 & $-3.5 /-3.7$ & 47.4 \\
$\mathbf{3 0 0 0}$ & $\mathbf{1 4}$ & $\mathbf{1 . 3 8} / \mathbf{2 . 9 5}$ & $\mathbf{1 . 9 3} / \mathbf{2 . 1 6}$ & $\mathbf{8 8 . 5}$ & $\mathbf{0}$ & $\mathbf{1 4 0 0}$ & $\mathbf{- 1 1 . 1} / \mathbf{- 1 1}$ & $\mathbf{4 0 . 4}$ \\
\hline
\end{tabular}


Table 4: Split of losses study in gross indicated efficiency

\begin{tabular}{|c|c|c|c|c|c|c|c|}
\hline & $\begin{array}{l}\text { SR } \\
{[-]}\end{array}$ & $\begin{array}{c}\text { Original } \\
{\left[\% \dot{m}_{f} H_{V}\right]}\end{array}$ & $\begin{array}{l}\text { Adiabatic } \\
{\left[\% \dot{m}_{f} H_{V}\right]}\end{array}$ & $\begin{array}{l}\text { Orig-Adiab } \\
{\left[\% \dot{m}_{f} H_{V}\right]}\end{array}$ & $\begin{array}{l}\Delta \mathrm{HT} \text { effect } \\
{\left[\% \dot{m}_{f} H_{V}\right]}\end{array}$ & $\begin{array}{c}\Delta \text { RoHR effect } \\
{\left[\% \dot{m}_{f} H_{V}\right]}\end{array}$ & $\begin{array}{c}\Delta \text { Global effect } \\
{\left[\% \dot{m}_{f} H_{V}\right]}\end{array}$ \\
\hline \multirow{4}{*}{ 1500_8 } & 1.38 & 42.0 & 47.3 & 5.3 & & & \\
\hline & 2 & 42.6 & 48.2 & 5.6 & -0.3 & 0.9 & 0.6 \\
\hline & 2.5 & 43.2 & 49.0 & 5.8 & -0.5 & 1.7 & 1.2 \\
\hline & 2.95 & 41.6 & 47.4 & 5.8 & -0.5 & 0.1 & -0.4 \\
\hline \multirow{4}{*}{ 1500_14 } & 1.38 & 39.4 & 43.7 & 4.3 & & & \\
\hline & 2 & 40.0 & 44.6 & 4.5 & -0.2 & 0.8 & 0.6 \\
\hline & 2.5 & 40.2 & 44.8 & 4.6 & -0.3 & 1.1 & 0.8 \\
\hline & 2.95 & 39.7 & 44.4 & 4.7 & -0.4 & 0.7 & 0.3 \\
\hline \multirow{4}{*}{ 3000_14 } & 1.38 & 43.8 & 47.6 & 3.8 & & & \\
\hline & 2 & 43.7 & 47.7 & 4.0 & -0.2 & 0.1 & -0.1 \\
\hline & 2.5 & 43.5 & 47.6 & 4.1 & -0.3 & 0 & -0.3 \\
\hline & 2.95 & 42.6 & 46.8 & 4.2 & -0.4 & -0.8 & -1.2 \\
\hline
\end{tabular}




\section{Appendix A.}

Heat transfer to the chamber is calculated with a modified Woschni-like model [24], where the convective heat transfer coefficient is obtained using Equation A.1:

$$
h=C D^{-0.2} p^{0.8} T^{-0.53}\left[C_{W 1} c_{m}+C_{W 2} c_{u}+C_{2} \frac{V_{d} T_{I V C}}{V_{I V C} p_{I V C}}\left(p-p_{0}\right)\right]^{0.8}
$$

where $C$ and $C_{2}$ are constants whose values are 0.12 and $0.001, D$ is the cylinder diameter, $p$ and $T$ are the in-cylinder instantaneous pressure and gas mean temperature respectively, $c_{m}$ is the mean piston speed, $c_{u}$ is the instantaneous tangential velocity of the gas in the chamber (see [24] for a detailed description of this term), $p_{0}$ is the pressure in motoring conditions assuming a polytropic evolution, and $C_{W 1}$ and $C_{W 2}$ are constants to be adjusted; $V_{D}$ is the displaced volume and $T_{I V C}, V_{I V C}$ and $p_{I V C}$ are the temperature, volume and pressure respectively at the intake valve closing. 